\title{
The Myth of Panic Spontaneity: Consideration of Behavioral and Neurochemical Sensitization
}

\author{
Andrea L.O. Hebb ${ }^{*}, 1,5$ Gregory J. Anger ${ }^{1}$, Paul D. Mendella ${ }^{2}$, Fuschia M. Sirois ${ }^{3}$, Robert W. Gilbert ${ }^{4}$ \\ and Robert M. Zacharko ${ }^{5}$
}

\author{
${ }^{I}$ Dalhousie University, Department of Pharmacology, Halifax, Nova Scotia, Canada \\ ${ }^{2}$ The Ottawa Hospital, Champlain District First Episode Psychosis Program, Ottawa, Ontario, Canada \\ ${ }^{3}$ University of Windsor, Department of Psychology, Windsor, Ontario, Canada \\ ${ }^{4}$ Dalhousie University, School of Health Sciences, Halifax, Nova Scotia, Canada \\ ${ }^{5}$ Carleton University, Institute of Neuroscience, Ottawa, Ontario, Canada
}

\begin{abstract}
Panic disorder is characterized by a progression of panic symptom severity with repeated attacks. Repeated panic episodes evoke heightened anticipatory anxiety, phobic avoidance and are typically associated with comorbid symptoms of depression. Due to the heterogeneity of the disorder, reliable neurochemical correlates attending panic have not been identified. However, variable neuropeptide interfacing with major and minor transmitter systems may modulate individual vulnerability to panic and account for variable panic profiles. The extensive colocalization of cholecystokinin (CCK) with other neurotransmitters, including dopamine (DA), enkephalin (ENK) and GABA, in specific central sites may influence various aspects of anxiety and panic. The behavioral correlates attending panic likely follow from variable neurochemical release and conditioning/sensitization. Clinicians maintain that recurrent panic attacks are spontaneous (unexpected, uncued) and fail to acknowledge the wealth of information implicating a prominent role for stressful life events in panic. Conditioning and sensitization of both behavior (e.g., fear-motivated) and neurochemical events (e.g., DA and $\mathrm{CCK}$ ) in response to uncontrollable stressors parallel the diverse heterogeneity of panic amongst clinical samples. Cholecystokinin-4, pentagastrin, lactate acid, and $\mathrm{CO}_{2}$ induce panic attacks that are dependent on subjective history, expectancy measures and panic profiles. Panic disorder is associated with chronic illness and familial sick-role modeling exacerbates the course of the illness. The current review outlines the evidence in support of a conditioning/sensitization model for panic, a model that may explain the variable efficacies of pharmacological interventions.
\end{abstract}

\section{INTRODUCTION}

Panic disorder is characterized by the repeated occurrence of panic attacks. During a panic attack, fear, shortness of breath, dizziness, heart palpitations, chest pain, sweating, faintness, paresthesia, nausea and cognitive symptoms including depersonalization and fear of losing control are typically reported [1]. Panic disorder is invariably associated with anticipatory anxiety [2,3] and is characterized by phobic avoidance [1]. Indeed, agoraphobic behavior routinely accompanies panic disorder and is more prevalent among females $[4,5]$. In any event, panic disorder with or without agoraphobia ordinarily persists for protracted periods and is accompanied by social and occupational impairments [6, 7], health risks [8-10] and comorbid psychiatric disturbances including changes in cognitive function [11], major depression [12, 13], schizophrenia [14] and substance abuse [15, 16].

Current neurochemical descriptors of panic are suggestive rather than persuasive and animal models of panic are provisional $[17,18]$. Inferences concerning central correlates

*Address correspondence to this author at the Department of Pharmacology, $15^{\text {th }}$ Floor Sir Charles Tupper Building, Dalhousie University, 5850 College Street, Halifax, Nova Scotia, B3H 1X5, Canada; Tel: 902-494-2600; Fax: 902-494-6294; E-mail: alohebb@dal.ca of panic have been derived from behavioral and neurochemical alterations attending systemic cholecysto-kinin $(\mathrm{CCK})$ administration in paradigms that simulate anxiety [19, 20]. The panic properties of systemic CCK [21-23] prompt suggestion that brain stem and spinal respiratory and cardiopulmonary CCK sites contribute to panic [24-26]. Panic attacks have been posited to occur in the absence of demonstrable precipitants (e.g., DSM-IV), despite evidence that stressful life events precede panic [2, 3, 27-33]. This observation is appealing, although the distribution, severity and controllability of stressful life events have received poor clinical documentation. In any event, the proposal that panic or the symptoms of panic are influenced by a stressor-CCK interface is intriguing. In fact, evidence implicating CCK and panic is convincing and a dopamine (DA)/CCK link to the disorder has been derived from neurochemical and behavioral evidence with nonhuman experimentation. Embedded in this matrix are issues pertaining to validity and generalizability of nonhuman experimentation and operational definitions of psychological dysfunction.

Dopamine-CCK colocalization has been detected in mesocorticolimbic DA neurons [34]. Identification of same vesicle DA/CCK [35] is consistent with speculation that DA and CCK co-release contributes to psychological disturbance [34]. At the very least, the variable influence of CCK on central DA should provide species-specific behavioral 
correlates of anxiety. Stressful life events may precede panic in vulnerable individuals. Accordingly, the responsivity of DA and CCK to aversive life events may influence the severity of panic symptoms. Mild stressors promote mesocorticolimbic DA [36] and CCK release [37-39] in rats, while variations of stressor intensity favor mesocorticolimbic diazepam-binding inhibitor [40], corticotropin-releasing factor [41] or $\beta$-carboline release (e.g., $\beta$-CCE and $\beta$-CCM) [42] in sites responsive to stressor associated alterations of DA and CCK. Taken together, diverse anxiogenic agents are released by stressors and the proposal that panic occurs in response to innocuous events is neither parsimonious nor appealing [43]. The present review suggests that conditioning and sensitization of anxiety may promote gradients of psychological dysfunction that eventuate in panic. Such an analysis suggests that life events are appraised soon after panic and rumination defines situational variables and provides a framework concerning the risk value of environmental events.

Animal models of conditioning and sensitization focus on long-term neurochemical alterations attending psychostimulant administration and the influence of transmitter variations on locomotor activity and stereotypy [44, 45]. Although locomotor activity and stereotypy are not indices of anxiety, the neural mechanisms underlying behavioral sensitization affected by stressors and psychostimulants are relevant to panic induction. In this respect, emergence and aggravation of panic symptoms may be occasioned by the conditioned pairing of anxiogenic agents, including CCK, and stressful life experience(s). The nature and severity of the stressor dictates site-specific central CCK release [46, 47] and the sensitivity of the brain sites examined [38]. Such variables may define vulnerability to panicogenic environmental events. Exacerbation of panic symptoms might be occasioned by recurrent stressors, panic experience and/or cues associated with such stimuli. In this regard, panic profiles may parallel nonhuman instances of sensitization while comorbid psychological disorders, including depression may outline the variable contributions of experiential and organismic factors [48], including gender susceptibility [49-56] as well as environmental context and conditioning [57-62] to the expression of pathological states. Parametric analyses reveal variability in the induction, persistence and magnitude of effects relative to the behavior examined and the brain sites involved. In view of the observation that stressors and acute and chronic psychostimulant administration influence DA $[63,64]$ and CCK turnover [38, 39, 65-67] and both DA [31, 68] and CCK $[69,70]$ alterations appear in panic patients, it is suggested that neurotransmitter sensitization may contribute to panic symptoms.

A sensitization/conditioning account of panic is appealing because (a) protracted anxiety has been associated with central DA variations in nonhuman [71] and human subjects [72-75], (b) CCK/DA colocalization is prevalent in mesocorticolimbic sites associated with arousal, reward, learning/conditioning [76], (c) anxiety among nonhuman subjects is readily induced by CCK administration in animal models of anxiety including the elevated plus maze [77] and (d) stressor-associated environmental cues influence behavioral [78-80] and neurochemical change [81, 82] reminiscent of the anticipatory anxiety associated with panic disorder. This review attempts to determine whether there is sufficient evidence to suggest that panic symptoms occur spontaneously or follow from conditioning of central DA/CCK activity induced by anxiety provoking conditions. A synthesis of such information is not meant to characterize the human disorder but rather to evaluate a limited subset of symptoms, including but not limited to, anticipatory anxiety.

\section{Central Dopamine Turnover: Prelude to Anxiety and Emergence of Panic Disorder}

Investigations of the pathophysiology of panic have focused on the serotonergic (5-HT), noradrenergic (NE), and the GABA-benzodiazepine systems [83-90] among other neurotransmitters. Nevertheless, several lines of evidence suggest that DA may be involved in anxiety $[68,91]$ and panic $[31,68]$. For anxiety, although there is a paucity of information for the role of DA in mediating clinical anxiety, mild stressors, that provoke mesocorticolimbic DA turnover, have demonstrable anxiogenic effects in the elevated plus maze [92-94] and fear potentiated startle [80] in rats. Such paradigm-associated anxiety, which is responsive to acute benzodiazepine administration, increased DA concentrations in the frontal and pyriform cortices, nucleus accumbens, septum, medial hypothalamus and amygdala [81, 95-98]. In the latter instance for panic, plasma and cerebrospinal homovanillic acid (HVA) concentrations, a DA metabolite, fail to discriminate panic and control subjects [29, 99, 100]. The lack of a neurochemical panic index is not without precedent since NE alterations, for example, have likewise failed to discriminate panic from non-panic subjects [101, 102]. Some laboratories have identified DA perturbations among panic patients with increased anxiety as measured on the Spielberger State Anxiety scale, augmented panic frequency in the 12 months preceding clinical interview and reduced symptom free periods relative to other panic patients $[30,31,68]$. Unfortunately, evidence for central DA and laboratory induced panic remains obscure. Laboratories that have assessed peripheral DA metabolites among normal subjects during laboratory exercises have failed to produce anxiety comparable to panic [103]. Indeed, there is no $a$ priori reason to suspect that innocuous laboratory challenges will induce panic in patients with the disorder [104]. Still, contrived laboratory situations provoke panic in some panic patients [57] suggesting that some individuals are more vulnerable than others to the impact of specific environmental encounters. It would be of considerable advantage to secure measures of central DA prior to, during and following panic induction in a laboratory situation.

Populations in which panic have been well documented include Parkinsonian patients and persons with schizophrenia. Despite the neurodegenerative nature of Parkinson's disease and the veiling of central neurochemistry by therapeutic interventions, panic in Parkinson's disease and schizophrenia provides subtle evidence for the involvement of DA in the phenomenology of panic-like states. It is interesting that divergent alterations in DA associated with Parkinson's disease and schizophrenia are associated with the elicitation of panic-like symptoms. While mesocorticolimbic contribution to behavioral sensitization following stressor encounter $[105,106]$ has received extensive 
documentation, nigrostriatal DA/CCK alterations may also alter sensitivity to stressors.

\section{Nigrostriatal Dopamine and Cholecystokinin: Anxiety and Panic-Like Behavior in Parkinson's Disease}

Parkinson's disease is characterized by insidious nigrostriatal DA and CCK depletion [107-112]. In addition to tremor, inertia, rigidity, bradykinesia, akinesia, flexed posture and gait disturbance, Parkinsonian patients experience mild depression and irritability as well as memory and attentional perturbations [111, 113-117]. Ldopa ordinarily ameliorates Parkinsonian associated motoric impediments but is ineffective in alleviating affective and cognitive symptoms of the disorder [111]. Advanced Parkinsonian stages reduce the efficacy of 1-dopa in alleviating motor disturbance and not surprisingly symptom free intervals [118]. Parkinsonian patients experiencing daily on/off episodes report increased instances of anxiety and depression during 1-dopa off stages [111, 119-121], prompting increased 1-dopa therapy [122]. Alleviation of mood disturbance and anxiety at this juncture may be attributable to the 1-dopa dose employed [123] or perhaps patient appraisal of restored motor function [73]. It should be considered that approximately $40 \%$ of 1-dopa treated Parkinsonian patients [124-126] exhibit a DA mesocorticolimbic-associated psychosis [127, 128]. Protracted 1-dopa treatment, therapeutic dose increases and episodic instances of pharmacological insensitivity to peripheral DA loading have been linked to the emergence of panic-like symptoms $(2.6 \pm 1.4$ panic attacks per day) among Parkinsonian patients [73, 122]. Nevertheless, panic frequency comparison between Parkinsonian and panic patients is obscured in the latter instance by investigations that fail to provide definitive panic statistics. Despite such difficulties, Parkinsonian panic (a) represents a relatively severe version of the disorder, (b) is distributed equally among male (45\%) and female subjects $(55 \%)$ [122] and (c) only emerges during latter stages of the disease (e.g., 60-70 years of age). In contrast, panic patients are most likely to experience a panic episode when they are middle-aged, rarely following age 65 , and the disorder is more prevalent among females [4]. Nigrostriatal degeneration may contribute to the paresthesia, burning sensations and discomfort emanating from the feet, chest or face immediately prior to panic [122]. Although a Parkinsonian focus on specific symptoms preceding panic has not been verified, such vigilance would parallel the documented physiological monitoring characteristic of panic subjects [129]. In this respect, distraction of Parkinsonian patients from antecedent neuromuscular perturbations attenuates panic [122].

It is unlikely that estrogen availability can account for panic among Parkinsonian patients. While panic frequency and severity could be reduced in female relative to male Parkinsonian patients owing to menopause onset, such predictions have not been verified. In fact, estrogen replacement has been associated with the alleviation [130] and the exacerbation [131] of panic symptoms in panic patients. Panic episodes characterized by pre-panic palpitation, chest discomfort, tightness of jaw, teeth grinding and muscle ache were attenuated by estrogen. In contrast, panic episodes lacking such a prominent motor profile are exacerbated by estrogen. In Parkinsonian patients, 1-dopa fluctuations and panic are often coupled to mood alterations such as depression. Increased estrogen levels in female rats have been associated with an increase in the rewarding value of brain stimulation from the medial forebrain bundle [132]. Taken together, the demonstration that (a) estrogen alleviates 1-dopa nigrostriatal perturbations, (b) 1-dopa fluctuations are associated with cognitive alterations including depression and psychosis (e.g., mesocorticolimbic DA alterations) and (c) the demonstration that 1-dopa motoric fluctuations and depression are associated with the development of panic among Parkinsonian patients preclude an estrogen-based argument. In effect, an estrogen hypothesis defining emergence, maintenance and exacerbation of panic in Parkinson's disease cannot readily account for the available data. In addition, the nature of the somatic experience per se does not appear to be relevant to the induction of panic. Rather, it seems that the intensity of the cognitive experience, regardless of the symptom cluster anticipated, may be sufficient to elicit panic. Such an interpretation suggests that panic emerges following rumination over perceptually defined salient cues in diverse pathological states (Fig. 1). In effect, panic among cardiac patients [133], depressed subjects $[13,28,134-142]$ or individuals with myasthenia gravis [9] is not surprising. Clearly, conspicuous neurochemical variations attending Parkinson's disease contribute to the emergence of somatic complaints and favor vigilance during treatment resistant intervals. In effect, fluctuations in Parkinsonian symptoms, coupled with pervasive, anticipatory stressors, may promote panic among treatment resistant Parkinsonian patients.

At first glance, it is not clear that panic among Parkinsonian patients contributes to the elucidation of the neural mechanisms associated with panic-like states and/or the putative influence of sensitization. These data merely suggest that panic-like symptoms in Parkinsonian patients follow from some neurochemical cascade elicited by DA denervation. Indeed, the appearance of panic-like symptoms in Parkinsonian patients coincides with the time course of mesolimbic DA denervation (e.g., VTA and prefrontal cortex) [143-145]. In addition to alterations in mesolimbic DA activity, post-mortem analyses of Parkinsonian brain tissue have also provided evidence for altered nigrostriatal CCK activity [107-110, 146]. Such changes in nigrostriatal CCK concentrations parallel indices of 1-dopa treatment resistance (e.g., 1-dopa resistant patients and animal model of Parkinson's disease [147-151] and symptom severity [107110]). As such, it is conceivable that nigrostriatal DA/CCK and mesolimbic DA alterations contribute to the eventual expression of panic among Parkinsonian patients owing to the gradual denervation of mesocorticolimbic sites from the substantia nigra. In effect, panic associated with nigral denervation and prompted by 1-dopa induced psychosis, suggests that a neurochemical depletion threshold may be attained during the latter stages of Parkinson's disease. Available evidence to date has certainly not established a causal role for mesocorticolimbic CCK and panic among Parkinsonian patients. At best, plasma CCK levels and postmortem CCK-binding provide provisional indices of augmented CCK turnover in specific subject populations experiencing varying levels of anticipatory anxiety [152, 153]. Nevertheless, anticipatory anxiety among Parkinsonian 


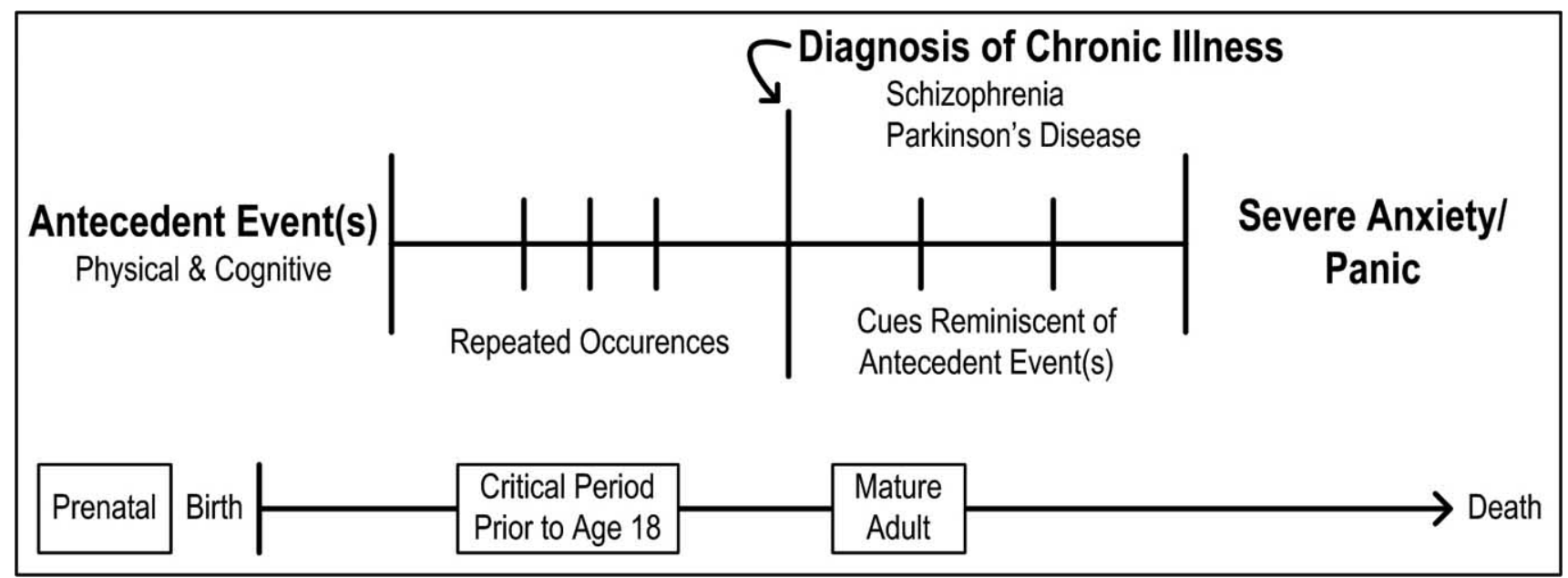

Fig. (1). Schematic diagram outlining the progression of events that leads to panic disorder. Initial antecedent events or mild stressful events elicit some physical or cognitive changes following the repeated occurrence of symptoms (subtle physical or cognitive) that culminate in severe anxiety states with disease progression. Interestingly, CCK alterations have been documented in schizophrenia and Parkinson's disease. Events may occur as early as before birth, with a critical period identified as prior to the age 18, and span across the lifetime.

patients may occur in response to the stressor-like experiences occasioned by the off stages of 1-dopa therapy (c.f. stressor induced CCK alterations in nonhuman subjects, $[38,39,67])$. Indeed, variations of mesocorticolimbic CCK availability between DA-denervated Parkinsonian patients experiencing panic and age, sex and disease matched subjects would be intuitively appealing. While such provisional arguments must be held in abeyance, panic-like symptoms among Parkinsonian patients coincide with (a) changes in nigrostriatal CCK availability during the late stages of the disease and (b) the emergence of presumably enhanced stressor periods among Parkinsonian patients (c.f. DA/CCK interface following stressor imposition in nonhuman subjects, [38, 39, 154, 155]). However, the appearance of panic among Parkinsonian patients experiencing gradual exacerbation of cognitive dysfunction (e.g., impairments in memory and attention and the development of psychoses, [111]) and motoric debilitation (e.g., during 1-dopa off periods and dyskinesias) lends support to a sensitization/conditioning hypothesis in the acquisition and expression of panic.

\section{Dopamine and Cholecystokinin in the Mesocorticolimbic System: Anxiety and Panic-Like Behavior in Schizophrenia}

Paranoid forms of schizophrenia have been associated with elevated anxiety as revealed by the Brief Psychiatric and Hamilton Anxiety Rating Scales [156-162]. These psychiatric patients routinely report experiencing a high incidence of daily life stressors (e.g., loss of social support, divorce, death of a loved one, impending job and/or residential changes and admission to a psychiatric facility) that exacerbate schizophrenic episodes [161, 163-172]. Moreover, repeated exposure to such life stressors increase anticipatory anxiety as revealed by exaggerated startle responsivity among individuals with schizophrenia [173, 174]. While atypical, severely stressful life events, including active military duty, for example, may precipitate psychotic episodes in vulnerable individuals [163], repeated experience with milder, stressful life events (e.g., loss of social support) over a few months has also led to schizophrenic symptom exacerbation, including psychosis [166]. In effect, elicitation and/or exacerbation of the symptoms of schizophrenia might be occasioned by a broad spectrum of life stressors, varying in severity and chronicity. Interestingly, panic and agoraphobia (e.g., $2.4 \pm 1.4$ attacks per week) have been reported among individuals with a history of paranoid schizophrenia (e.g., >4 years) by several different laboratories [72, 175-178]. The panic symptoms experienced by individuals with schizophrenia appear to represent a moderately severe panic course reminiscent of that experienced by Parkinsonian patients [179]. Characteristically, individuals with schizophrenia who experience paniclike symptoms tend to be socially introverted, consistent with pervasive paranoia and/or embarrassment associated with psychotic episodes $[175,178]$. The frequency of paniclike symptoms among individuals with schizophrenia coincides with the psychotic episodes that are associated with anxious cognition, including rumination over agoraphobic fears and increased somatic perturbations [175, $178,180,181]$. Indeed, preoccupation with and attention to somatic and cognitive perturbations punctuated with varying degrees of psychosis may contribute to panic symptoms in individuals with schizophrenia. While somatic monitoring in schizophrenia would parallel the physiological vigilance characteristic of panic [129], cognitive monitoring may be specific to schizophrenia. Individuals with schizophrenia are undoubtedly cognizant of the progression of schizophrenic symptomatology (see [182] for discussion of suicide prevalence among individuals with schizophrenia). However, severe schizophrenic illness may preclude cognitive intervention strategies with demonstrated efficacy on panic symptomatology in Parkinson's patients [122] and panic patients [183]. Nevertheless, panic symptom attenuation in schizophrenia coincides with decreased psychotic episodes (e.g., alprazolam, 2.5 - 5mg/day, [177, 178]) or reduced agoraphobic associated behavior (e.g., imipramine, $50 \mathrm{mg} /$ day, [175]). At this juncture, it is not readily apparent whether the neural mechanisms underlying schizophrenia are likewise conducive to the expression of panic. For example, psychosis has been demonstrated in panic patients. The appearance of psychosis among panic patients is related to the duration of panic ( $>10$ years), severity (>3 panic 
attacks/day) of panic symptomatology and the presence of agoraphobia [184-186]. Moreover, the relative risk for schizophrenia among panic patients appears to be conspicuously increased relative to the general population [185]. Taken together, central neurochemical alterations accompanying psychopathology and/or the gradual emergence of conditioned behavior (e.g., agoraphobia) may influence the course of panic-like symptoms.

Hypersensitivity of mesocorticolimbic DA activity, as measured by DA binding [187, 188], DA mRNA [189], positron emission tomography (PET) [190] and ${ }^{123}$ I-IBZM SPECT [191, 192] among individuals with schizophrenia, appears to coincide closely with the expression of positive schizophrenic symptoms such as delusions and hallucinations [193, 194]. Notably, positive symptoms of schizophrenia are associated with social and agoraphobic fear [161]. It should be underscored that negative symptoms of schizophrenia such as poverty of speech, flattened affect and psychomotor retardation are not associated with hypersensitivity of mesocorticolimbic DA activity (see [195] for review) or panic. It should be considered that mesocorticolimbic hypersensitivity might follow from the chronic neuroleptic regimens employed to attenuate delusions and hallucinations [196]. Typically, delusions, hallucinations and phobic avoidance assessed by the Minnesota Multiphasic Personality Inventory (MMPI), Clinical General Impression (CGI) and the Brief Psychiatric Rating Scale (BPRS) [157, 159, 195, 196] are exacerbated over the course of the illness. The gradual exacerbation of schizophrenic symptoms has prompted suggestion that conditioning and/or sensitization of mesocorticolimbic DA (see [181, 197-199] for review of mesocorticolimbic DA and cognition; c.f. amphetamine psychosis, [200-203]) underlie(s) expression of at least some of the behaviors associated with schizophrenia [91, 187, 204, 205]. In addition to alterations of central DA activity, there are some data that outline a putative contribution of central CCK to the etiology and maintenance of schizophrenia [206-209]. Postmortem determinations have revealed increased CCK concentrations in the striatum and mesencephalon [210, 211] and reduced CCK availability in the amygdala and hippocampus [212-214] as well as concomitant reductions of CCK mRNA in the temporal and frontal cortices in neuroleptic treated individuals with paranoid schizophrenia relative to controls matched for age $(65.8 \pm 6.8$ years $)$, morbidity (e.g., heart disease and cancer) and postmortem delay (16.6 \pm 4.2 hours) [215]. Available studies to date have clearly not established a relationship between central CCK and panic in individuals with schizophrenia and investigations documenting central CCK variations among individuals with paranoid schizophrenia typically fail to document any symptoms reminiscent of panic. It is interesting, however, that postmortem CCK determinations in brain tissue have verified patterns of CCK activity within specific brain sites associated with positive and negative symptoms of schizophrenia. On the one hand, positive symptoms of schizophrenia, precipitated by increased DA activity $[195,196,216,217]$, are associated with a greater reduction in frontal cortex CCK mRNA compared to the temporal cortex. On the other hand, negative symptoms of schizophrenia are associated with reduced CCK mRNA in the temporal cortex, amygdala and hippocampus [215].
Panic attacks fluctuate with psychosis severity and it would be of interest to determine mesocortical CCK activity (e.g., PET scan) among individuals with schizophrenia during a panic episode. Curiously, neuroleptic strategies for schizophrenia (e.g., haloperidol) increase striatal and mesolimbic CCK concentrations $[218,219]$ and increase CCK binding (e.g., decreasing CCK tissue levels) in several cortical areas in nonhuman subjects that persist for several weeks [219221]. Panic-like symptoms and exacerbation of schizophrenia following neuroleptic withdrawal [175, 222, 223] has been associated with increased CCK activity and concomitant release of the anxiogenic substances, corticotropinreleasing factor [224] and diazepam-binding inhibitor [225, 226].

While the panic properties of CCK-4 have been empirically documented among panic patients and healthy volunteers [21, 227], demonstration of the panic inducing properties of CCK-4 in individuals with schizophrenia is unavailable (c.f. CCK-8S administration in schizophrenia, [208, 228-234]). Recall that in individuals with schizophrenia, social and agoraphobic fear have been reported to precede panic attacks [175]. Interestingly, in rats, social isolation has been associated with an upregulation of $\mathrm{CCK}_{2}$ receptors in the frontal cortex [235]. It is conceivable that some personality variables associated with schizophrenia (e.g., social introversion or social alienation) provide indices of panic susceptibility following CCK-4 challenge. For example, the intensity of somatic, affective and cognitive responsivity to CCK-4 (e.g., Panic Symptom Scale) in panic patients has been related to anxiety sensitivity (e.g., Anxiety Sensitivity Index) and self-alienation scores derived from the MMPI Social Inversion Subscales [22]. It would be of interest to determine the effects of $\mathrm{CCK}_{2}$ antagonists, which attenuate the panicogenic effects of CCK-4 in panic patients [236], on agoraphobic fear and panic symptoms in individuals with schizophrenia (c.f. neuroleptic properties of $\mathrm{CCK}_{2}$ antagonists in nonhuman preparations, [237]). If $\mathrm{CCK}_{2}$ antagonists were efficacious in the treatment of panic symptoms among individuals with schizophrenia (e.g., psychosis, agoraphobia and/or social avoidance), it is conceivable that alterations in mesocorticolimbic $\mathrm{CCK}_{2}$ receptor activity sustain expression of both schizophrenic and panic symptoms. Moreover, it should be considered that current therapeutic interventions (e.g., haloperidol), which promote increases in CCK activity in the frontal cortex of nonhuman subjects, might contribute to panic-like responses among individuals with schizophrenia. Taken together, alienation, introversion, panic and psychotic exacerbation may be associated with variants of enhanced CCK sensitivity and/or over activity of central DA and contribute to the expression of panic symptoms in individuals with schizophrenia.

Panic-like symptoms among individuals with schizophrenia are reminiscent of those reported by Parkinsonian patients and may be occasioned by (a) the prevalence or perceived prevalence of stressful life events, (b) alterations of central DA/CCK availability associated with chronic illness and/or (c) the chronicity of therapeutic interventions. Interestingly, Parkinsonian panic coincides with reduced 1dopa efficacy and 1-dopa induced psychosis. Furthermore, autoradiographic data suggest comparable mesocorticolimbic DA receptor variations (e.g., frontal cortex and nucleus 
accumbens) in paranoid schizophrenia and Parkinsonian patients experiencing 1-dopa psychosis [145, 238-243]. The saliency of mesocorticolimbic DA/CCK alterations to the promotion of panic in individuals with schizophrenia and Parkinson's disease is obvious. Taken together, the repeated encounters with stressful life events may facilitate panic in Parkinsonian patients, individuals with schizophrenia and panic patients (see Fig. (1)). The clinical vantage (DSM-IV) typically asserts that stressful life events do not participate in the precipitation or maintenance of panic. However, panic often emerges in clinical populations with demonstrated vulnerability to stressful life events (e.g., depression, schizophrenia, Parkinson's disease). In order to determine whether stressful life events contribute to the provocation of panic symptomatology in individuals with schizophrenia, Parkinson's disease and panic disorder, the cumulative and proactive influence of stressors must be determined (e.g., sensitization).

\section{Anxiogenic Indices Associated with Stressor Exposure: Nonhuman and Human Experimentation}

Anxiety among nonhuman subjects has been defined as the behavioral response to unpredictable, novel or threatening stimuli, including uncontrollable footshock, in anxiety paradigms $[78,80,94,244]$. Yet, it remains to be determined whether footshock is a suitable stressor in assessing anxiolytic efficacy. Examination of repeated anxiety provoking situations to the provocation of panic necessitates comparison of animal models that parallel the human condition. To date, adequate animal models of panic are lacking. It should be considered that fear conditioning (e.g., startle and freezing) in nonhuman subjects may provide a behavioral analogue of the anticipatory anxiety associated with panic disorder. It has been demonstrated, for example, that rats exposed to apparatus cues previously associated with footshock exhibited increased DA turnover in the prefrontal cortex [82] and amygdala [81] which was attenuated by low dose diazepam administration $(1-5 \mathrm{mg} / \mathrm{kg})$. Conditioned fear paradigms employ rather mild stressors relative to paradigms assessing the behavioral repercussions of footshock. In any event, conditioned fear (e.g., freezing) has been reliably associated with elevated plasma ACTH, corticosterone and prolactin concentrations for at least 14 days post-stressor in rats [245]. In humans, conditioned fear or fear-enhanced startle has been linked to psychological disorders in which sustained and exaggerated reactivity to environmental stressors appears fundamental. For example, enhanced startle response has been routinely associated with posttraumatic stress disorder [246], schizophrenia [247] and panic [248, 249]. Interestingly, clinical investigations have demonstrated an enhanced startle reflex (e.g., eye-blink and heart rate) in response to a startle probe (e.g., binaural burst of $110 \mathrm{~dB}$ white noise, $50 \mathrm{msec}$ duration) previously associated with graphic photographic slides (e.g., wounds or mutilated bodies) in normal subjects [250]. In panic patients, exaggerated fear-potentiated startle response has been detected in response to the threat of electric shock [57]. Anticipation of electric shock (e.g., $1.5 \mathrm{~mA}, 50 \mathrm{msec}$ conducted through the median nerve of the wrist) administered during the final 10 seconds of a 45 second threat but not a 50 second no-threat condition, signaled by differential light cues, increased startle in panic patients relative to healthy controls. This startle response was largest in younger panic patients (e.g., <40 years) who also reported an increased frequency of panic attacks within the week prior to testing relative to older panic patients and age matched control subjects [251]. Taken together, the absence of a detailed retrospective clinical characterization of putative stressors and inadequate documentation of salient cue associated variables prevent an accounting of the ensuing panic histories of disparate panic subjects. Ultimately, startle latencies provide a potential measure of the developmental history of anticipatory anxiety and panic emergence. Indeed, Grillon et al. [251] reported that anticipated cue associated challenges in a simulated startle paradigm among young and older panic subjects elicit variable patterns of experimental compliance which influenced participation and anxiety induction.

Surprisingly, the contribution of mild stressors to anxiety induction in clinical applications has been neglected. It is intriguing that amygdaloid [252] and mesencephalic [253] input to the parabrachial nucleus sustains cardiovascular arousal and the VTA participates in the detection of salient and non-salient cues in rats [254]. Interestingly, panic patients with frequent panic episodes (e.g., >5.6 \pm 2.3 attacks/week) exhibit heightened cardiovascular arousal, increased sympathetic/autonomic alterations and increased anxiety in response to innocuous stimuli relative to panic patients with less frequent panic attacks (1.5 \pm 0.5 attacks/week) and normal subjects [255, 256]. Perhaps, sustained rumination and hypervigilance concerning encounters with situational challenges heighten anxiety. The contribution of such variables to the induction of panic certainly merits consideration. Yet, alterations of central anxiogenic activity accompanying panic and the identification of the parameters of putative stressors or the perceived saliency of environmental stimuli to the evocation of panic attacks have not been established. The demonstration that anticipation of stressful encounters influences CCK activity in humans [152, 153, 257] is certainly consistent with such an interpretation. Repeated low psychostimulant doses in rats were associated with alterations in CCK concentrations and CCK mRNA expression, which could be detected for several weeks following the last injection $[65,66]$. Likewise, exposure to life stressors prior to age 19 has been documented to precipitate anxiety, depression and/or panic in some individuals [258, 259]. Indeed, familial illness and sick role behavior may also be salient to illness onset and the course of the psychological disturbance [260, 261]. Moreover, childhood behavioral problems (e.g., social withdrawal, anxiety/depression and aggression/delinquency) and the degree of emotional involvement demonstrated by parents to offspring with schizophrenia have been associated with poor prognosis, including psychotic relapse and comorbid affective disturbances [262, 263]. It should be noted parenthetically that nonhuman primates raised under stressful conditions (e.g., variable foraging demands) reveal aberrant behavior patterns (e.g., hyperactivity, clinging and behavioral inhibition) [264] and protracted increases in cerebrospinal corticotropin-releasing factor (CRF) availability [265] in adulthood compared to age- and sexmatched control subjects. To date, evidence for the enduring influence of site-specific central CCK alterations among 
human or nonhuman primates exposed to early life stressors are unavailable. In effect, aberrant parental practices, sickrole modeling and excessive rumination may precipitate central CCK alterations that contribute to symptom exacerbation and panic emergence. Moreover, some investigators have suggested that decreased lymphocyte and cerebrospinal CCK-8 concentrations in panic patients may reflect enhanced CCK receptor sensitivity, reduced CCK receptor availability or perhaps compensatory reduction of CCK-8 concentrations secondary to increased CCK-4 activity $[69,70]$. It should be considered that neurotransmitters colocalized with CCK, including DA, participate in the production or exacerbation of some of the symptoms associated with panic disorder. Dopamine alterations may be peculiar to panic patients with considerable anxiety and a relatively severe panic course [31, 68]. Moreover, DA alterations have been linked to the development of social phobia, a severe form of agoraphobia $[100,266]$. Taken together, the nature of the panic experience and the frequency of stressful encounters may precipitate CCK release and determine the saliency of environmental conditions to panic induction.

\section{Cholecystokinin, Anxiety and Panic Attacks}

Molecular forms of CCK are cleaved from prepro-CCK and include CCK-8 sulfated (S), pentagastrin (CCK-5) and CCK-4 which are degraded by aminopeptidase (see [76] for review). Cholecystokinin-8S is the predominant central form of CCK and found in high concentrations in the cerebral cortex, nucleus accumbens, basal ganglia, thalamus, hypothalamus, periaqueductal grey, olfactory tubercle, olfactory bulb, VTA, some brain stem nuclei and the spinal cord [206, 267-272]. Cholecystokinin is colocalized with DA in the mesencephalon [273], CRF in the paraventricular nucleus of the hypothalamus [274], oxytocin in the supraoptic and paraventricular nucleus of the hypothalamus [275], substance $P$ in the central gray projecting to the spinal cord [276], GABA in the amygdala, frontal cortex and hippocampus $[277,278]$ and enkephalin in the hippocampus ([279]; (see [280, 281] for review of antagonistic role of CCK and enkephalin in stress, anxiety, cognition and pain). As such, it is not surprising that CCK has been implicated in nocioception [282], learning and memory [283] as well as ingestive [284, 285], sexual and reproductive behavior [286] and panic [76, 287].

Central and gastrointestinal CCK receptors have been identified. The $\mathrm{CCK}_{1}$ receptor distribution predominates in the gastrointestinal tract, area postrema, nucleus tractus solitarius, posterior nucleus accumbens, amygdala, septum, hypothalamus, dorsal raphe, cerebral cortex, ventral tegmental area, substantia nigra and hippocampus in rats and mice [288-290]. Sedative [230], ingestive [291], kindling [292], exploration [293], locomotion [294, 295] and cognitive [296] properties of the $\mathrm{CCK}_{1}$ receptor have been amply demonstrated. Central $\mathrm{CCK}_{2}$ receptors are distributed in the brainstem solitary complex, nigrostriatal, mesolimbic and mesocortical sites among nonhuman and human subjects and appear to play an anxiogenic (or pro-panic) role [297, 298]. Mice lacking $\mathrm{CCK}_{2}$ receptors are less anxious, as measured by increased exploratory behavior in the elevated plus maze paradigm, than their wild type littermates [299,
300]. Although, peripheral and central CCK-8S administration in nonhuman subjects has been associated with anxiety in the elevated plus maze [301,302] and lightdark paradigms [244], CCK-8S induces nausea and gastrointestinal malaise in human subjects [303, 304]. Either "illness behavior" and anxiety are not adequately differentiated in nonhuman subjects following CCK-8S administration or fundamental differences exist between the influence CCK agonists have on peripheral CCK receptors (i.e., those of the alimentary canal) in nonhuman and human subjects. In contrast, the selective $\mathrm{CCK}_{2}$ agonist, CCK-4, induces anxiety in nonhuman subjects $[20,305]$ and promotes panic in panic patients and normal subjects [21, 23]. The differential propensity of CCK-8S and CCK-4 to provoke anxiety and/or panic in human subjects as well as rats and mice may be attributable to species variations [306], differential brain region sensitivity (e.g., amygdala, prefrontal cortex and nucleus accumbens, [307, 308]), drug route [309, 310] and/or paradigm specificity [308]. Clearly, discrepancies between clinical and nonhuman studies necessitate examination of methodological variables including drug schedule and experiential factors that influence sensitivity to CCK challenge and anxiety (panic) induction. The ensuing discussion will examine the contributions of CCK-8S, CCK-4 and pentagastrin to the provocation of anxiety in nonhuman and clinical subjects, the evidence supporting the contention that stressful life contribute to CCK-induced panic and the nature of panic symptoms in response to CCK administration. The diverse clinical profiles of panic suggest developmental stages of psychological dysfunction. Sensitization of central DA/CCK activity and cognitive processes (e.g., rumination and anticipatory anxiety) may underlie variability in effective pharmacological management of panic (Fig. 2).

\section{Cholecystokinin Induced Anxiety: Nonhuman Models}

Chronic diazepam and alprazolam withdrawal have been associated with increased anxiety in human $[311,312]$ and nonhuman subjects [313]. Interestingly, chronic benzodiazepine treatment in rats decreases neural responsivity to microiontophoretic CCK-8S application in the frontal cortex and hippocampus [287, 314]. In contrast, termination of chronic diazepam treatment increases hippocampal and cortical CCK-8 binding in the rat [315]. In mice, the $\mathrm{CCK}_{2}$ receptor antagonist, Cl-988, dose dependently (0.001-1.0 $\mathrm{mg} / \mathrm{kg}^{-1}$ ) antagonized the anxiogenic effects associated with diazepam withdrawal [313]. In rats, flumazenil (4 mg/kg i.p.) significantly antagonized the anxiogenic effects of the $\mathrm{CCK}_{2}$ agonist, CCK-8S and the anxiolytic-like effects of the $\mathrm{CCK}_{2}$ antagonist, L-365, 260 [310]. Moreover, rats rated anxious with respect to performance in the elevated plus maze exhibited a reduced benzodiazepine receptor density and increased CCK-8S binding in the frontal cortex relative to non-anxious counter-parts [315]. These data suggest that benzodiazepines suppress CCK-8S activity in the prefrontal cortex of anxious mice [20]. Moreover, the dose and nature of the CCK fragment employed suggests site-specific sensitivity to anxiogenic drug administration. It is conceivable that CCK fragments exert differential influence on central areas associated with anxiety emergence. Indeed, the central amygdaloid nucleus is conspicuously more 


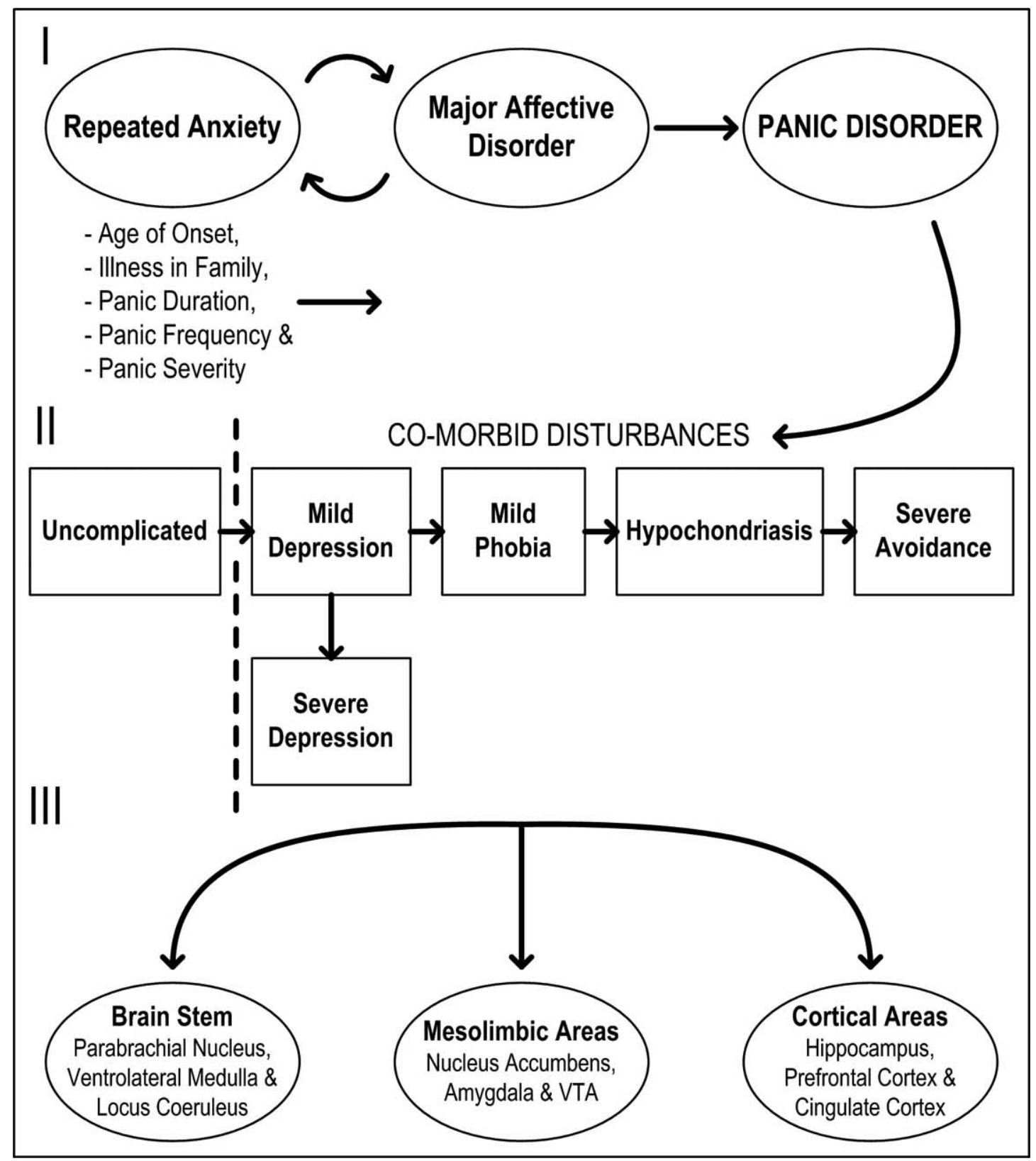

Fig. (2). Schematic illustration of the involvement of repeated anxiety episodes in panic (I), the developmental stages, or course, of panic and the precipitating variables that affect its course (II) as well as some of the central sites hypothesized to be involved in panic disorder (III). I. Repeated anxiety may precipitate major affective disorder while episodes of depression may lead to further increases in anxiety. Reciprocal influences on individual states of anxiety and depression may be influenced by subjective factors including chronic illness in the family, subject history or other stressors. Panic evolves following some time and the temporal parameters associated with the appearance of panic symptoms among various clinical populations have not been clearly determined. II. Panic symptoms, once present, may consist primarily of autonomic symptoms including cardiovascular perturbations or cognitive symptoms including depersonalization and fear of losing control without accompanying phobic or depressive symptoms. More commonly panic disorder is complicated with depression of varying severity, mild phobia, hypochondriasis, and/or severe avoidance behavior. The varying types of panic classifications may represent different developmental stages of panic. Moreover, age of onset, illness in the family, panic duration, panic frequency and panic severity may influence the progression of panic from uncomplicated panic episodes to panic with comorbid symptoms of depression and phobia. Moreover, such factors may also influence pharmacological management of panic. III. The developmental stages of panic appear to be characterized by prominent symptoms that may involve brain stem structures, mesolimbic areas or cortical areas. Uncomplicated panic, for example, may be primarily associated with cardiovascular and respiratory perturbations (e.g., brainstem) although anxiety (e.g., amygdala) and rumination (e.g., nucleus accumbens, VTA, prefrontal cortex) are also present. Co-morbidity with depression or phobia would typically involve mesencephalic (e.g., VTA), mesolimbic (e.g., nucleus accumbens, amygdala) and cortical areas (e.g., prefrontal cortex and cingulate gyrus). Repeated panic attacks likely alter the neurochemical substrates of the psychological disorder according to the sequence/frequency of panic intrusion or perhaps inter-panic interval. It is intriguing that the effectiveness of imipramine and alprazolam in alleviating panic symptoms varies with the severity of comorbid depressive symptoms or agoraphobia. 
sensitive to CCK-4 than the prefrontal cortex or the nucleus accumbens in the startle paradigm [308]. Moreover, in exploration paradigms (e.g., light-dark task and elevated plus maze), low doses of ceruletide (CCK-8S agonist, $100 \mathrm{ng} / \mathrm{kg}^{-}$ $\left.{ }^{1}\right)$ and pentagastrin (CCK-5 agonist, $500 \mathrm{ng} / \mathrm{kg}^{-1}$ ) are only anxiogenic among mice previously exposed to the stress of overcrowding. Significantly elevated doses of ceruletide and pentagastrin are required to induce comparable levels of anxiety among rats and mice housed in non-crowded conditions $[77,316]$. Furthermore, investigations in nonhuman primates indicate that intravenously administered CCK-4 dose dependently $\left(0.5-4 \mathrm{mg} / \mathrm{kg}^{-1}\right)$ increased fear and defensive behaviors according to the baseline anxiety scores of animals and their social hierarchical position [317]. Apparently, antecedent environmental experiences interact with the nature of subsequent pharmacological challenges in provoking anxiety.

The demonstration that (a) anxious mice exhibit reduced benzodiazepine receptor density and increased CCK-8S binding in the frontal cortex relative to non-anxious mice [315], (b) strain-specific sensitivity in fear-motivated behavior appears among rats [318], (c) strain-specific behavioral and neurochemical variations appear among mice exposed to the elevated plus maze [319] and (d) differential behavioral and neurochemical sensitivity emerges among divergent inbred and outbred mouse strains challenged with anxiogenic agents (e.g., footshock, [320]) certainly provides evidence for the influence of genetic variables to the expression of anxiety. It is intuitively consistent to suspect that genetic variables and antecedent environmental stressors likewise contribute to the attenuation, exacerbation or maintenance of clinical anxiety. Alterations in $\mathrm{CCK}_{2}$ receptor sensitivity in panic patients may also accompany increased anxiety following CCK administration. In view of differential post-mortem CCK receptor binding between panic prone Parkinsonian patients and individuals with schizophrenia, panic subjects would likely demonstrate variable central CCK receptor sensitivity to exogenously administered CCK fragments. Current empirical evidence supports altered basal CSF CCK concentrations in panic patients relative to control subjects $[69,70]$. The inadequacy of such a comparison is apparent and functional indices of CCK turnover and/or CCK receptor sensitivity in discrete central sites among CCK challenged panic subjects are required.

Potential parallels between nonhuman experimentation employing CCK-8S and clinical data is compromised owing to the ineffectiveness of this CCK fragment in provoking anxiety in humans. Accordingly, comparison of nonhuman CCK-induced anxiety with chronic anxiety syndromes, including panic, in human subjects is limited to studies concerned with CCK-4 availability and $\mathrm{CCK}_{2}$ receptor activation (e.g., [23, 321, 322]). However, the functional significance of central $\mathrm{CCK}_{1}$ receptor sensitivity and density in areas involved in central respiratory and cardiovascular activity (e.g., the nucleus tractus solitarius and parabrachial nucleus) [253, 323, 324], motivation (e.g., nucleus accumbens) [325], attention (e.g., VTA) [254], and cognition (e.g., prefrontal cortex) [181] to anxiety among nonhuman subjects requires consideration. It will be recalled that panic patients engage in considerable somatic monitoring [129]. The neurocircuitry of brainstem sites involved in the modulation of respiratory and cardiovascular function as well as possible neurochemical correlates attending increased vigilance and a possible relation to panic have been discussed previously [326]. It is conceivable that hypochondriasis in panic may stem from alterations in $\mathrm{CCK}_{1}$ receptor sensitivity following protracted vigilance.

Consideration of parallels between behavioral profiles drawn from animal models of anxiety and clinical panic symptoms should focus on behaviors that reflect comparable aspects of anxiety. For example, it appears that conditioned fear (e.g., anticipatory anxiety) and exploratory tendencies in novel environments (e.g., the response of an organism to a potentially threatening stimulus) provide indices of diverse aspects of anxiety [327]. Repeated exposure of rats to the elevated plus maze as an analogue of anticipatory anxiety has been criticized owing to the resistance of such behavioral tests to the anxiolytic influence of benzodiazepines [328, 329]. While questions relating to the validity of the elevated plus maze in evaluating anticipatory anxiety may be relevant, arguments pertaining to the efficacy of benzodiazepine intervention strategies may be misleading. For example, the nature of the anxiety experienced in the plus maze with repeated apparatus exposure undoubtedly varies with successive exposures to the stressor-like influence of the paradigm. In rodents the pattern of CCK release from specific mesocorticolimbic sites varies according to the nature and severity of the stressor [38, 39, 154, 155, 218]. In effect, repeated exposure of animals to the mild, anxiogenic influence of the elevated plus maze may augment CCK release and effect protracted alterations of CCK receptor sensitivity. In effect, the nature of the CCK associated experience has been altered and pharmacological responsivity might likewise be expected to vary. Taken together, reduced propensity of diazepam in alleviating anxiety associated with repeated maze exposure suggests that the neurochemical correlates of the stressor have been altered (e.g., conditioning/sensitization) [45, 330]. It is suspected that identification of some of the conditions (e.g., genetic and environmental) contributing to inter-individual sensitivity to CCK challenge paradigms, including efficacious anxiolytic applications, in nonhumans may parallel variable therapeutic efficacy of anti-panic drugs in clinical trials (Fig. 2).

\section{Cholecystokinin Challenge, Panic Induction and Clinical Investigations}

The selective $\mathrm{CCK}_{2}$ agonists, CCK-4 and pentagastrin, induce panic in healthy volunteers and panic patients [21, 25, 321]. Acute, oral L365, 260 administration $(50 \mathrm{mg}, 90$ minutes prior to CCK-4 challenge) attenuates CCK-4 (50 $\mu \mathrm{g})$ [331] but not lactate [322] induced panic in panic patients. The specificity of L365, 260 in attenuating CCK but not lactate-induced panic may suggest that there are different types of panic. Curiously, an acute, oral dose of the $\mathrm{CCK}_{2}$ antagonist CI-988 (50 or $100 \mathrm{mg}$ ) 2 hours prior to CCK-4 challenge failed to attenuate CCK-4 $(20 \mu \mathrm{g})$ induced panic in both normal subjects [332] and panic patients [333]. At this juncture it is not clear whether the efficacy of L365, 260, relative to CI-988, in attenuating CCK-4 panic is attributable to experimental protocol, pharmacological properties or panic profile. Nevertheless, it is likely that CCK-induced 
panic symptoms including tachycardia, nausea and dyspnea stem from a CCK influence on selective brain stem nuclei. Cognitive variations attending CCK-induced panic, including anticipatory anxiety, are most likely attributable to mesolimbic and cortical sites secondary to brainstem activation (see [334, 335] for an accounting of such a conclusion with respect to cerebral blood flow and fMRI activity profiles in response to CCK-4 administration, respectively [321, 331]). While clinical responsivity to CCK4 is well documented, there is considerable behavioral variability in the responsivity of panic patients and healthy volunteers to $\mathrm{CCK}$ challenge. For example, the panic inducing properties of relatively large CCK-4 doses (e.g., 25 or $50 \mu \mathrm{g})$ or pentagastrin $(0.1-0.6 \mu \mathrm{g} / \mathrm{kg})$ have been reliably demonstrated in several laboratories $[21,23,25,321,336$, 337]. However, elevated anxiogenic drug administration (a) confounds potential central variations describing interindividual responsivity of clinical patients to $\mathrm{CCK}$ challenge and (b) prevents detection of the relative vulnerability of healthy control subjects to panicogenic agents. Indeed, the efficacy of CCK-4 in provoking panic-like symptoms appears to be dose dependent. For example, among panic patients the panic distribution was $17 \%(10 \mu \mathrm{g}), 64 \%(15$ $\mu \mathrm{g}), 75 \%(20 \mu \mathrm{g}), 75 \%(25 \mu \mathrm{g})$ and $91-100 \%(50 \mu \mathrm{g})$ following the respective CCK challenge doses [336]. In an accompanying investigation, proportional panic frequencies of $11 \%(9 \mu \mathrm{g}), 17 \%(25 \mu \mathrm{g})$ and $47 \%(50 \mu \mathrm{g})$ were detected following CCK challenge doses administered in control subjects [338]. These data suggest varied CCK response thresholds among panic patients that are lower than those of control subjects, which exhibit graded responsivity to CCK challenge. The lower threshold for response found in panic patients relative to controls, with respect to CCK-4 dosage, has been confirmed [339, 340]. Selection of the respective challenge doses of $\mathrm{CCK}$ obscures investigation of sensitization and/or conditioning by discounting subject variability and clinical history. Such an approach is unfortunate and counterproductive. In effect, the obvious differential sensitivities of clinical populations to CCK challenge require documentation of threshold CCK doses (e.g., initial challenge). Ensuing responsivity of panic patients to $\mathrm{CCK}$ should, at the very least, consider rechallenge with sub-threshold doses of CCK-4. The interval pertaining to $\mathrm{CCK}$ re-exposure for clinical investigations is not readily available although data derived from nonhuman experimentation suggests that protracted intervals may be required (see [244] for discussion of temporal influences on CCK sensitization). Individuals with panic display variable clinical histories, including age of onset, familial history, frequency and severity of panic as well as comorbid symptoms of depression and/or agoraphobia (Fig. 2). The most appealing of such clinical accounts include instances where panic frequency and the appearance of agoraphobia are temporally exaggerated, suggesting an incremental basis to panic induction (e.g., [137]). Intuitively, it is appealing to consider that sub-threshold doses of CCK-4 in panic patients produce behavioral effects that mirror clinical panic exacerbation. To date, consideration of such factors and the potential contribution of these variables to long-term responsivity to CCK-4 challenge have not been adequately assessed (c.f. [45]). The anxiogenic efficacy of CCK in animals and nonhuman primates was clearly dependent upon antecedent environmental experiences, including the differential stressor influence of the paradigm considered $[316,317]$. Such a comparison to panic patients appears to be a logical one. To be sure, it must be demonstrated that individual stressor and panic histories interact with CCK challenge to influence panic thresholds. Taken together, panic patients and control subjects demonstrate differential sensitivities to the panicogenic properties of CCK-4. Moreover, demonstration of enhanced CCK sensitivity following CCK-4 re-challenge underscores the need to (a) delineate an inter-drug interval conducive to behaviorally enhanced responsivity, (b) establish behavioral sensitivity to previously non-panicogenic doses of CCK-4 and (c) describe patient histories pertaining to effective challenge and rechallenge doses of $\mathrm{CCK}$ and the temporal parameters supporting sensitization.

The hypothesis that individuals exhibit differential sensitivities to the panicogenic properties of CCK-4, or to other panicogenic agents, is intriguing. At the very least, these data permit subject characterization according to organismic variables (e.g., baseline anxiety levels) and experiential factors (e.g., age of onset and severity of panic disorder). In effect, age of onset may provide one index of panic severity. For example, panic patients with a history of early life stressors, including childhood separation disorder or a family history of panic disorder with agoraphobia, exhibit an earlier age of onset of panic disorder relative to individuals who fail to report such events [341]. In this respect, severity of panic disorder may be operationally defined according to illness duration. Such an analysis would necessitate assessment of the cognitive repercussions associated with such an illness and individual perception of the saliency of such a stressor. In addition to illness duration, the severity of panic may be qualitatively assessed by panic frequency. Parkinsonian patients and individuals with schizophrenia with panic secondary to chronic illness have a relatively severe panic profile (e.g., $2.4 \pm 1.4$ panic attacks/week) [122, 175]. The appearance of panic attacks among late-stage Parkinsonian patients is interesting. In the clinical population, panic attacks rarely occur following age 65. Interestingly, a lower ${ }^{3} \mathrm{H}-\mathrm{CCK}-8$ hippocampal binding density [257] as well as decreased CCK mRNA in the hypothalamus and cerebral cortex [342] and increased CCK concentrations in the cerebral cortex [343] have been detected among rats 18-29 months of age relative to younger animals (i.e., 2-10 months). It would be of interest to determine if comparable alterations in CCK activity are evident in the amygdala and nucleus accumbens, for example, in animal models of Parkinson's disease. An analysis of mesolimbic sites may provide a CCK associated index of panic susceptibility that addresses the apparent delay of panic onset among Parkinsonian patients. Surely, subjective characteristics including identification of events precipitating panic (e.g., Parkinson's disease, schizophrenia and childhood anxiety separation) would evoke differential sensitivities to the panicogenic properties of CCK-4 among diverse clinical samples.

To date, clinical reports of CCK-4 induced panic, fail to identify subject characteristics or experiential variables that may influence responsiveness to CCK in normal subjects and panic patients. It should be noted parenthetically that panic attacks induced by CCK-4 occur within seconds (e.g., $20 \pm 3$ 
seconds) following systemic administration and appear to be similar to naturally occurring panic attacks (e.g., mean duration $20.7 \pm 7.6$ seconds) [21]. It appears that the assumption of panic spontaneity has been gleaned from the rapid induction of panic following a large, bolus injection of CCK-4 $(50 \mu \mathrm{g})$. Moreover, the onset of "spontaneous" or induced (e.g., $\mathrm{CO}_{2}$ ) panic symptoms over a longer period of time (e.g., time to peak intensity $>10$ minutes) is inconsistent with a panic description afforded by DSM-IV criteria [344, 345]. Such clinical definitions are counterintuitive particularly when it is considered that patients exhibiting panic attacks with latencies exceeding 10 minutes achieve peak intensity ratings comparable to those of panic patients with rapid symptom onset (see [345-347]). Curiously, immediate panic onset was characterized by increased phobic frequencies and elevated anticipatory anxiety while patients with more protracted latencies prior to panic onset exhibited more generalized anxiety symptoms [345]. Persistent fear of anticipated panic episodes has been recently proferred as a diagnostic criterion for panic disorder [344, 348]. While panic spontaneity is predicated on reduced latencies, it has been well documented that panic patients may experience a paucity of symptoms (e.g., 1-2 symptoms) prior to the emergence of symptom clusters (e.g., >4 symptoms). For example, lifethreatening interpretation of vestibular symptoms including fear of fainting, chest pains, breathing difficulty or choking sensations have led to catastrophic interpretations [2]. Not only does the occurrence of limited symptoms prior to the development of panic and the "fear of fear" criterion argue against spontaneity but also is suggestive of a developmental panic course. Recent operational definitions of panic, including limited and situational panic attacks, contradict previous versions of panic spontaneity and inadvertently support the argument that panic attacks evolve from gradual symptom exacerbation. If there were indeed a developmental course of panic, influencing the temporal appearance and severity of symptomatology, panic patients would not only exhibit differential sensitivities to the panicogenic properties of CCK-4 but also exhibit enhanced responsivity to panicassociated cues. Indeed, in some instances the panicogenic properties of placebo have been demonstrated in panic patients [349]. Intuitively, panic attacks occurring in response to placebo procedures are suggestive of expectancy and likely reflect augmented basal anxiety levels. At this juncture, available clinical data do not readily identify laboratory setting and procedural details pertaining to blood pressure assessment and/or intravenous protocols as correlates of enhanced behavioral responsivity in clinical samples. Such an interpretation is hardly surprising, despite the accumulation of clinical evidence which argues for the lack of such an effect (c.f. [21, 350, 351]). To be sure, if environmental cues favor panic emergence; illness duration, severity of panic attacks, agoraphobia and associated rumination would likewise be expected to influence behavioral responsivity. Indeed, while a $20 \mu \mathrm{g}$ oral dose of yohimbine induces panic in panic patients with more than 2.5 panic attacks/week, this identical dose of yohimbine is without effect among panic patients with a panic frequency of less than 2.5 panic attacks/week [352, 353]. Likewise, elevated basal indices of anxiety, increased panic frequency in the week prior to testing and panic associated somatic reporting were reliably associated with yohimbine induced panic attacks relative to panic patients which failed to report such indices $[352,354]$. Similarly, intravenous lactate elicited panic in $75 \%$ of panic patients reporting a panic frequency exceeding 1 panic attack/week while no panic attacks emerged with such challenge among panic patients reporting frequencies of less than 1 panic attack/month [355]. It should also be considered that experimental setting and patient expectations including anticipatory reactivity and stressor controllability may influence the course of panicogenic challenge paradigms [356-358]. For example, panic patients provided with the expectancy of anxiety in $\mathrm{CO}_{2}$ challenge investigations have a demonstrable increase in reported distress and elevated panic incidence relative to patients who have been instructed that control over $\mathrm{CO}_{2}$ inhalation can be achieved [358]. Moreover, experimental protocols that minimize expectancy of panic averted the panicogenic properties of yohimbine ( $20 \mu \mathrm{g}$ orally) $[352,354]$. It should be underscored that anxiety-rating scales appear to provide inadequate assessment of anticipatory anxiety and are likely influenced by patient compliance and demand characteristics. In contrast, physiological measures (e.g., blood pressure, heart rate and cortisol responses) while providing more objective measures of anxiety [251, 357, 359, 360] are not invariably sensitive to expectancy. To be sure, it is rather curious that panic patients fail to report anticipatory anxiety in challenge studies or to provide physiological measures of expectancy yet consistently report a hyper-vigilant state consisting of somatic monitoring or environmental vigilance which may serve as predictors of panic. It should also be considered that clinical investigation, in some instances, permits patient-assisted low dose benzodiazepine maintenance. In addition, failure to substantiate plasma drug concentrations prior to challenge (e.g., [336]) may complicate experimental interpretation and mask pre-test anxiety measures. In view of the observation that lactate-, yohimbineand $\mathrm{CO}_{2}$-induced panic are influenced by rumination pertaining to panicogenic control and panic expectancy, it is likely that such factors also influence behavioral responsivity to CCK-4 administration. Further to this point, characterization of control subjects responsive to CCK-4 administration may provide salient information regarding panic vulnerability. For example, it has been demonstrated that 6 of 62 normal subjects subsequently reported a panic attack during the 12 month follow-up period following initial $\mathrm{CO}_{2}$ challenge [361]. Unfortunately, the temporal distribution of life events preceding the panic attack as well as detailed subjective and familial history were inadequately detailed. Although the proactive influence of CCK-4 on subsequent panic attacks are not available, a parsimonious accounting of this peptide would favor the prediction that CCK-4 experience contributes to the development of panic. Clinical strategies would accordingly employ therapeutic interventions prior to the "second" panic episode that may interrupt, or at best delay, conditioning and/or sensitization of CCK dependent symptoms [330].

\section{Pharmacological and Cognitive Management of Panic Disorder: Implications for Putative Differential Sensitivities Among Panic Patient Samples}

Pharmacological management of panic disorder often includes chronic administration of imipramine (150-300 $\mathrm{mg}$ /day) with the benzodiazepine alprazolam $(2-8 \mathrm{mg})$ as needed, although amitriptyline $(150 \mathrm{mg} /$ day $)$ and clomipramine (150-225 $\mathrm{mg} / \mathrm{day})$, the irreversible monoamine 
oxidase inhibitor phenelzine (45-90 $\mathrm{mg} /$ day), the reversible monoamine oxidase inhibitors moclobemide (300-600 $\mathrm{mg} /$ day) and brofaromine (150 $\mathrm{mg} /$ day) and certain selective 5-HT reuptake inhibitors are also used [183, 362-372]. Chronic imipramine administration in nonhuman subjects is associated with reduced cerebrospinal and plasma $\mathrm{NE}$ concentrations [373-375] and 5-HT [376, 377]. In rats, chronic administration of imipramine decreases the electrophysiological activity of the locus coeruleus [378]. Interestingly, imipramine has demonstrable effects on panic frequency with limited effects on phobic and agoraphobic behavior [379]. In contrast to imipramine, the efficacy of alprazolam in ameliorating panic cannot be attributed to enhanced GABA/benzodiazepine receptor influence [380]. Indeed, diazepam and alprazolam augment benzodiazepine receptor density in the frontal cortex, hypothalamus and hippocampus ([381]; c.f. benzodiazepine receptor binding in panic patients, [382]) and influence central NE [85, 373] and 5-HT activity [383] to a comparable degree in nonhuman and human subjects. Yet diazepam is therapeutically sterile in the treatment of panic [384] while alprazolam reduces panic frequency, anticipatory anxiety and phobic symptoms [385]. Taken together, these data would suggest that cascading neurochemical alterations associated with benzodiazepineGABA receptor variations contribute to the therapeutic efficacy of chronic alprazolam treatment. In any event, these data suggest that pharmacological management of panic should be directed toward specific symptoms characterizing the psychological disorder. Nevertheless, the efficacy of pharmacological interventions among panic patients is often confounded by attrition, patient compliance, relapse following progressive drug taper [386-388] and drug side effects [384, 389-395]. Alprazolam for example, is associated with a lower attrition (5\%), than imipramine $(20 \%)$ or placebo $(54 \%)$. The reduced attrition associated with alprazolam is most likely due to its reduced therapeutic latency (e.g., within one week) relative to imipramine (e.g., 4-8 weeks) or placebo on panic frequency, anxiety episodes, anticipatory anxiety and phobic symptoms [390, 395-397]. In the rat, acute $(5$ or $10 \mathrm{mg} / \mathrm{kg}$ ) and chronic $(10 \mathrm{mg} / \mathrm{kg}, 21$ days) imipramine administration fails to attenuate fear potentiated startle [398]. In contrast, acute administration of alprazolam $(1.0,2.0,3.0 \mathrm{mg} / \mathrm{kg}) 30$ minutes prior to test, dose dependently attenuated startle [399]. The relative efficacies of alprazolam and imipramine in antagonizing fear potentiated startle in rats suggests that alprazolam may be more effective in influencing central sites underlying expression of startle and conditioned behavior, including the central nucleus of the amygdala (c.f. [400-404]) (Fig. 2). Notably, central and basolateral nuclei amygdaloid neurochemical perturbations associated with benzodiazepine-GABA receptor variations including alterations in GABA and glutamate [252, 405-407] most likely potentiate the anxiolytic and anti-panic properties of alprazolam. The patient characteristics provided by Andersch et al. [390] as well as Klein [394] and Taylor et al. [395], for example, suggest that alprazolam is more effective than imipramine in alleviating anticipatory anxiety preceding panic (e.g., anticipatory intervals associated with panic expectancy, Sheehan Patient-Rated Anxiety Scale). In retrospect, it is curious that clinical reports outlining the panicogenic effects of CCK fail to acknowledge a role for anticipatory anxiety in panic. Such putative differences in anticipatory indices among panic and control subjects participating in CCK challenge paradigms, as well as paradigms that manipulate anticipatory anxiety, pose serious obstacles to detractors of an expectancy hypothesis. In effect, the demonstrable heterogeneity of treatment efficacy associated with chronic imipramine and alprazolam may well follow from the influence of such agents on variable developmental stages of panic disorder.

It is presumed that panic is a heterogeneous disorder comprised of patients who experience uncomplicated panic or, conversely, a complicated panic disorder syndrome consisting of panic with comorbid symptoms of mild or major depression and/or panic with varying degrees of phobic avoidance. While it has been well documented that recurrent anxiety episodes provoke depressive episodes, repeated anxiety episodes together with the affective disturbance of depression may evoke panic (see [137] for review). In any event, the temporal parameters and the contribution of intra- and inter-individual environmental precipitants have not been clearly established (Fig. 2). Conceptually, the heterogeneity of panic types may coincide with differential stages of panic development. Regardless of psychiatric compartmentalization of panic, panic disorder is invariably progressive with evidence of symptom exacerbation. The adoption of limited panic and situationally provoked panic classifications and arbitrary acceptance of $\mathrm{ad}$ hoc patient categories provides tacit acceptance of a developmental course in panic. To be sure, it would be reasonable to suggest that premorbid patient characteristics, the duration of the illness, age of onset as well as the frequency and severity of panic episodes influence the expression or exacerbation of depression and phobic avoidance among individuals with panic disorder. Similar comparisons have been provided for depression and schizophrenia and there is no a priori reason to suspect a differential developmental course for panic disorder. In fact, uncomplicated panic and panic with comorbid depression and/or extensive phobic avoidance, on the other hand, may operationally define panic severity. Moreover, while responsivity to $\mathrm{CCK}$ challenge may vary with panic history, age of onset, illness duration and panic frequency, the efficacy of panic interventions would also be expected to vary with such variables (Fig. 2).

Pretreatment measures of panic have revealed diminished panic frequency, anxiety (Hamilton Anxiety Rating scale), depression, phobia, paranoia and help seeking behaviors. Moreover, placebo may be sufficient to attenuate panic symptoms for at least the duration of an eight-week clinical trial [408, 409]. In general, it appears that subjects who respond to placebo have a less severe course of panic and high expectations for pharmacological improvement. Alprazolam and imipramine are equally effective in attenuating panic symptoms associated with uncomplicated panic disorder [370, 409]. It should be noted parenthetically that clinical accounts of panic reveal a depression comorbidity rate of $60-75 \%[410,411]$. Chronic imipramine intervention (150 mg/day, 4-8 weeks) is relatively effective in ameliorating panic symptoms in panic patients early in the course of the disorder where mild depressive symptoms are also detectable [412, 413]. Conditions favoring imipramine treatment include a relatively short duration of illness (e.g., 
1-2 years), younger age of onset ( $<40$ years), comorbid mild depression and panic with no or limited agoraphobia characterized by respiratory distress [138, 414-416]. In contrast, alprazolam is less effective in alleviating panic symptoms among panic patients with comorbid mild depression [417] unless the disorder is accompanied by increased phobic avoidance and increased anticipatory anxiety. In such instances, alprazolam and imipramine are equally effective in alleviating panic symptoms [370]. Amitriptyline (150 mg/day) and phenelzine $(60 \mathrm{mg} /$ day $)$ are also equally effective in alleviating panic symptoms associated with mild depression [418]. Patients with panic disorder with comorbid major depression are typically more anxious, fearful of criticism, unassertive and markedly impaired in various social areas compared to non-depressed panic patients [138, 419]. Moreover, panic patients with comorbid major depression are more likely to report earlier age of panic onset $(<20$ years), previous psychiatric hospitalizations, suicidal tendencies and increased suicide attempts than non-depressed panic patients $[6,420]$. Typically, the perceived severity (e.g., disability scales) and frequency of panic among such patients is likewise increased [418, 421, 422] and phenelzine (75 mg/day) is more effective than imipramine and amitriptyline in ameliorating panic symptoms associated with major depression [418, 423, 424]. Conditions favoring alprazolam treatment include age over 40, lower baseline levels of anxiety (Hamilton Anxiety Rating Scale) and mild phobic symptoms (Phobia Rating Scale) [409]. Although the presence of phobic anxiety and avoidance is associated with a longer duration of illness [425] and an increased severity of panic disorder as measured by disability subscales [426], panic patients over the age of 40 tend to have a later age of panic onset (e.g., later clinical admission) [409] and evidence suggests that subjects with a later panic onset have a less severe and more treatment responsive illness [341]. Illness severity measures (e.g., disability scale and agoraphobic avoidance) are more pronounced in panic patients who experience a greater frequency of panic attacks ( $>2$ attacks/week) compared to patients who experienced panic attacks at a lesser frequency (<2 attacks/week) and higher doses of alprazolam (5.2 \pm 1.5 $\mathrm{mg}$ vs $3.0 \pm 1.6 \mathrm{mg}$ ) are required to establish panic free periods [255, 427, 428]. At higher doses (150-250 mg/day, 4-8 weeks) imipramine is also effective in attenuating the severity of panic symptoms including measures of fear in nondepressed panic patients with agoraphobia although subjects continued to experience panic attacks [429]. Hypochondriasis may also be a form of sickness behavior that responds favorably to alprazolam. For example, alprazolam (5.8 mg/day 6 weeks) reduced hypochondriasis (e.g. Illness Behavior Questionnaire, [430]) including preoccupation with bodily sensations and fear of physical illness yet had no effect on panic frequency [431]. Extensive phobic avoidance, hypochondriasis and relatively high levels of anticipatory anxiety have been associated with nonresponsiveness of panic symptoms to conventional drug therapies [432, 433]. Data suggests, however, that the reversible monoamine oxidase inhibitor, brofaromine, may be effective in ameliorating panic attack frequency associated with severe agoraphobia [434]. Typically cognitive and behavioral interventions, in addition to drug therapies, are utilized to reduce panic symptoms in otherwise treatment resistant patients although cognitive interventions may be employed prior to pharmacological therapy early in diagnosis [372, 412, 421, 435-437]. Moreover, the introduction of cognitive, behavioral or performance-based strategies in the treatment of panic disorder sustains improvement of panic symptoms during drug treatment and following drug taper [438-440]. Despite the demonstrated efficacy of most anti-panic medication in the attenuation of panic symptoms early in the disorder, panic progression typically necessitates adoption of protracted cognitive strategies. Such interventions may reduce the saliency of association cues since pharmacotherapy alone does not yield adequate long-term management of panic disorder. In fact, the effectiveness of performance-based treatment in alleviating phobic symptoms relies on subjective perceptions pertaining to performance adequacy or coping ability in specific tasks [441]. Taken together, baseline symptoms, panic frequency, depression severity, phobic avoidance and anticipatory anxiety are useful predictors of pharmacological efficacy on outcome scales.

It has been well documented that early diagnosis of panic facilitates the success of pharmacological and cognitive intervention strategies [137, 384, 385, 432]. Indeed, data derived from various laboratories suggest that the duration of panic disorder [425], the severity and frequency of panic attacks and agoraphobic avoidance [442] prior to treatment is negatively correlated with the efficacy of ensuing therapy. In many instances, illness chronicity appears to complicate treatment owing to the induction of agoraphobia and impairments of social interaction [425, 434]. Illness severity as measured by patient reports of more severe panic and agoraphobic symptoms, increased psychiatric hospitalizations and longer duration of panic were predictive of poor pharmacological and cognitive management compared to less severe courses of panic disorder [442]. Moreover, illness severity may also reflect an earlier age of onset and panic may be precipitated by childhood events. For example, investigators have alluded to a relationship between a history of childhood anxiety, including separation anxiety, school phobia and familial illness and the development of panic in childhood or early adulthood [260, 394, 421, 434, 443-445]. Nonhuman primates raised under stressful conditions (e.g., variable foraging demands) exhibit aberrant behavior (e.g., hyperactivity, clinging and behavioral inhibition among others) [264]. Studies of nonhuman primates also indicate that infant temperament and qualities of the maternal-infant relationship influence the intensity of separation anxiety. For example, peer-raised animals show exaggerated and persistent attachment behaviors (e.g., exhibit more despair on separation) and display alterations in central NE, DA and 5-HT concentrations relative to maternally fostered animals which may impede the infants later ability to cope with lifestressors [446]. Clinically, increased anxiety in childhood typically follows illness of a primary caregiver, with the imminent perception of possible death [447] and appears to be salient to the eventual induction of panic, [260, 447, 448]. Notably, illness and separation can exacerbate the frequency and severity of panic attacks [421, 447]. Not surprisingly, familial illness and sick role behavior can also influence the efficacy of anti-panic medications. For example, children who developed panic disorder following a bout of school 
phobia respond well to the selective 5-HT reuptake inhibitor, citalopram $(20 \mathrm{mg} / \mathrm{day})$. Interestingly, however, panic free periods were temporally shorter among children whose mothers also suffered from panic disorder with agoraphobia [449]. Presentation of panic symptomatology following a history of childhood anxiety is typically more severe relative to panic symptoms in patients without a history of childhood anxiety [141, 421, 434, 450]. For example, at the time of initial panic assessment, patients with childhood anxiety are characterized by greater agoraphobic avoidance as measured by agoraphobic avoidance scales (e.g., Fear Questionnaire), a longer duration of panic (e.g., childhood onset), more frequent panic attacks and more severe anxiety as indicated by clinical global severity scales (e.g., frequency of panic attacks/week, intensity of anticipatory anxiety, degree of avoidance and degree of social role impairment) [451]. Patients with a childhood history of anxiety disorders also have a significantly higher rate of comorbidity including social phobia, generalized anxiety disorder, obsessivecompulsive disorder, major depression and a family history of anxiety disorders [445]. Moreover, panic disorder following a history of childhood anxiety is typically resistant to pharmacological treatment [434] and requires lengthy cognitive and psychological counseling [421, 447]. Taken together, clinical accounts of panic and the heterogeneity of individual treatment responses to alprazolam and imipramine, among others, reveal diversity in prominent symptoms associated with panic disorder. The presence of depression and agoraphobia reflect illness severity and influence the responsivity of panic symptoms to treatment. Moreover, untreated or inadequately treated panic symptoms worsen with time and the progression from uncomplicated to complicated instances of panic are predicated on panic frequency, severity of symptoms, age of onset, coping strategies and familial setting.

The clinical manifestation of panic among panic patients, individuals with Parkinson's disease and schizophrenia among others suggests that stressful life events or the perception of uncontrollable or unpredictable aversive events may influence the emergence and exacerbation of anxiety. Repeated panic experiences influence cognitive activity and may enhance vigilance and somatic monitoring. In nonhuman subjects, the intensity, duration, controllability, predictability and chronicity of an aversive encounter as well as experiential factors $[452,453]$ influence the effectiveness of stressors in modifying ensuing behavioral and neurotransmitter activity. Moreover, presentation of the cues associated with the initial stressor experience can influence the expression of pathology. Similarly, among individuals with diverse panic histories, fear motivated behavior including anticipation of subsequent panic attacks and the development of avoidance behavior are modulated by prior stressor experience (e.g., previous panic attacks) and the cues associated with prior panic episodes (e.g., assignment of a weighting scheme to specific environmental events, [454]). The contribution of mild, stressful life events and DA to the emergence and maintenance of panic symptoms requires clarification. It would be difficult to characterize Parkinson's disease, schizophrenia or major affective disorder with comorbid panic symptoms as mild disturbances from either physiological or cognitive vantages. Yet, sensitization of DA mechanisms and putative involvement with panic disorder is predicated on the assumption that pathology may be augmented owing to progressive encounters with mild, unpredictable and/or uncontrollable life events. It is conceivable that cognitive variations immediately preceding onset of Parkinson's disease or schizophrenia, for example, provide rather subtle cues pertaining to alterations in the emotional and/or physical lability of the individual. Nevertheless, repeated or relatively protracted indices of such cues may be sufficient to sensitize central neurochemical substrates. In addition, mild stressors or environmental cues that elicit comparable cognitive variations may sustain the neurochemical correlates of initial experiences. In effect, such a scenario may eventually define the profile of symptoms and determine vulnerability (e.g., latency to the emergence of psychological dysfunction) to anxiety disorders, including panic. The emergence of panic necessitates the coupling of conditioned/sensitized DA activity, the behavioral manifestation of such neurochemical activity and central CCK. Interestingly, data collected in this laboratory suggest that mild stressors reliably induce anxiety among nonhuman subjects and more importantly that these anxiogenic indices are exaggerated following central CCK administration at protracted intervals. In effect, long-term responsivity to stressful life events, CCK activation or crosssensitization between CCK and stressors is dependent on the mild nature and the contextual cues associated with anxiogenic challenge. Notably, initial imposition of a severe stressor or re-exposure of animals to an equally severe stressor or a high dose of CCK does not induce a dissociable increase in behavioral responsivity. The duration of panic disorder prior to the emergence of symptom exacerbation would provide (a) an operational index of the time course of neurochemical sensitization and (b) provide evidence for, but not necessarily identification of, the influence of patientspecific stimuli contributing to illness progression. In accordance with such an argument, imipramine and alprazolam would be expected to exert an influence when administered relatively early in the course of the disorder (e.g., soon after sensitization) and likely prior to clinical diagnosis of panic. Moreover, the pharmacological efficacy of imipramine and alprazolam on panic symptoms in CCKchallenge studies would interact with the dose(s) of CCK employed and panic profile. For example, clinical investigations examining the anti-panic influence of imipramine on CCK-4 induced panic among panic patients revealed that a variable dose of imipramine (150-300 $\mathrm{mg}$ /day) and a fluctuating duration of imipramine treatment (3-26 months) was necessary to attain an eight week panic free period following a bolus injection of CCK-4 (50 $\mu \mathrm{g})$ which subsequently attenuated panic attacks to a rechallenge dose of CCK-4 $(20 \mu \mathrm{g})$. Notably, $18 \%$ of panic patients who had previously panicked with CCK-4 $(50 \mu \mathrm{g})$ reported a panic attack upon rechallenge (20 $\mu \mathrm{g}$ CCK-4) [331]. Unfortunately, with respect to CCK-induced panic, panic was predicated on large CCK challenge doses and, from a pharmacological vantage, investigators failed to isolate specific patient characteristics and panic profiles that enhance pharmacological responsiveness or at the very least dictate the dose of imipramine required to attenuate panic naturally. At best, imipramine and alprazolam may prevent exacerbation of panic. Indeed, withdrawal of such therapeutic interventions ordinarily results in the re- 
emergence and in some cases exacerbation of panic symptoms. To date, the role of CCK in the reemergence of panic symptoms following alprazolam withdrawal remains enigmatic (see [428, 455-457]). However, it should be emphasized that the symptoms diagnostic of Parkinson's disease, schizophrenia or other disorders associated with the emergence of panic worsen over time. In parallel, panic symptoms also are temporally exaggerated. In effect, once sensitization has occurred, the profile and/or progression of panic symptoms are relatively dependent upon host factors. Notably, the conditioning of both somatic and cognitive panic symptoms over time and the demonstrated long-term resistance of panic symptomatology to therapeutic interventions support an argument for sensitization [204, 458].

\section{CONCLUSION}

There is no evidence that panic attacks are spontaneous. However, available evidence points to a common etiology across disorders associated with panic. Clinically, the gradual exacerbation of anxiety-like behavior and the appearance of panic are reminiscent of the behavioral and neurochemical alterations in nonhuman subjects repeatedly exposed to anxiogenic stimuli. In fact, it is likely that panic disorder represents a constellation of sensitized behavioral responses (e.g., limited symptom attacks to a full blown panic attack with phobic avoidance) and the inter-subject variability may follow from the differential influence of organismic and experiential variables. Such claims are not surprising as sensitization/conditioning models have been offered as explanations for Parkinson's disease (e.g., 1-dopa fluctuations), schizophrenia and depression. Moreover, it appears that variations of CCK availability in specific central sites are associated with variable panic profiles. To date, a conditioning/sensitization hypothesis of panic disorder has not been adequately assessed. To be sure, the nature of the challenge stimuli, including dose and drug schedule, as well as possible cross-sensitization of specific anxiogenic challenges with stressful life events and the long-term repercussions associated with challenge-induced panic in both normal and panic patients must be considered. Moreover, adequate measures of anticipatory anxiety are clearly needed. CCK availability is linked to colocalization of other neurotransmitters in distinct central sites which suggests that CCK may modulate (a) different aspects of anxiety, including anticipatory reactions to anxiogenic stimuli, (b) variations in cognitive arousal and vigilance and (c) sensitization and conditioning of behavior (e.g., phobic associations) and central neurochemical activity (e.g., DA and GABA). Likewise, multiple anxiogenic agents and putative neurotransmitters or neuromodulators in the mesencephalon, the limbic system as well as the prefrontal cortex and brain stem sites would appear to participate in the promotion of anxiety. In fact, it may be the failure of clinical investigations to appreciate the complex interaction of CCK with other neurotransmitter systems, the sensitization of such systems and the contributions of subjective factors to the nature and temporal progression of anxiogenic release that prevents adequate treatment of panic disorder. Conversely, it should be considered that elimination of panic might only occur with prophylactic treatment. In any event, identification of specific subject populations at risk for later development of panic disorder, necessitates empirical demonstration of differential thresholds for panic evocation (e.g., challenge studies) and detailed clinical histories which would demonstrate the circumstances under which panic can be reliably induced (e.g., environmental and cognitive). Taken together, a comprehensive analysis of panic and panic-like states requires attention to the specific details outlined in this review regarding dose of challenge, interchallenge intervals, precise subject characteristics and panic history. Undoubtedly, exacerbation and maintenance of panic in chronic conditions, including Parkinson's disease and schizophrenia, and the divergent panic profiles among panic patients involves sensitization and conditioning of neurochemicals (e.g., DA/CCK) and increased rumination that ultimately influence the effectiveness of therapeutic regimens.

\section{ACKNOWLEDGEMENTS}

A Research Development Grant (RWG) provided by the Faculty of Health Professions, Dalhousie University supported this work.

\section{REFERENCES}

[1] Shioiri T, Someya T, Murashita J, Takahashi S. The symptom structure of panic disorder: A trial using factor and cluster analysis. Acta Psychiatr Scand 1996; 93: 80-6.

[2] Kenardy J, Fried L, Kraemer HC, Taylor CB. Psychological precursors of panic attacks. Br J Psychiatry 1992; 160: 668-73.

[3] McNally RJ, Lukach BM. Are panic attacks traumatic stressors? Am J Psychiatry 1992; 149(6): 824-6.

[4] Grant BF, Hasin DS, Stinson FS, et al. The epidemiology of DSMIV panic disorder and agoraphobia in the United States: Results from the national epidemiologic survey on alcohol and related conditions. J Clin Psychiatry 2006; 67: 363-74.

[5] Lepine J-P, Lellouch J. Diagnosis and epidemiology of agorophobia and social phobia. Clin Neuropharmacol 1995; 18(2): S15-S26.

[6] Massion AO, Warshaw MG, Keller MB. Quality of life and psychiatric morbidity in panic disorder and generalized anxiety disorder. Am J Psychiatry 1993; 150(4): 600-7.

[7] Sherbourne CD, Wells KB, Judd LL. Functioning and well-being of patients with panic disorder. Am J Psychiatry 1996; 153: 213-8.

[8] Chignon J-M, Lepine J-P, Ades J. Panic in cardiac outpatients. Am J Psychiatry 1993; 150(5): 780-5.

[9] Paradis CM, Friedman S, Lazar RM, Kula RW. Anxiety disorders in a neuromuscular clinic. Am J Psychiatry 1993; 150: 1102-4.

[10] Yeragani VK, Pohl R, Balon R, Ramesh C, Glitz D, Sherwood P. Risk factors for cardiovascular illness in panic disorder patients. Neuropsychobiology 1990; 23: 134-9.

[11] Ludewig S, Geyer MA, Ramseier M, Vollenweider FX, Rechsteiner E, Cattapan-Ludewig K. Information-processing deficits and cognitive dysfunction in panic disorder. J Psychiatry Neurosci 2005; 30: 37-43.

[12] Rush AJ, Zimmerman M, Wisniewski SR, et al. Comorbid psychiatric disorders in depressed outpatients: demographic and clinical features. J Affect Disord 2005; 87: 43-55.

[13] Weissman MM, Wickramaratne P, Adams PB, et al. The relationship between panic disorder and major depression: A new family study. Arch Gen Psychiatry 1993; 50: 767-80.

[14] Goodwin R, Lyons JS, McNally RJ. Panic attacks in schizophrenia. Schizophr Res 2002; 58: 213-20.

[15] O'Brien MS, Wu LT, Anthony JC. Cocaine use and the occurrence of panic attacks in the community: A case-crossover approach Subst Use Misuse 2005; 40: 285-97.

[16] Maier W, Minges J, Lichtermann D. Alcoholism and panic disorder: Co-occurrence and co-transmission in families. Eur Arch Psychiatry Clin Neurosci 1993: 243: 205-11.

[17] Blanchard DC, Griebel G, Blanchard RJ. The mouse defense test battery: Pharmacological and behavioral assays for anxiety and panic. Eur J Pharmacol 2003; 463: 97-116. 
[18] Charney DS. Neuroanatomical circuits modulating fear and anxiety behaviors. Acta Psychiatr Scand Suppl 2003; 417: 38-50.

[19] Frankland PW, Josselyn SA, Bradwejn J, Vaccarino FJ, Yeomans JS. Intracerebroventricular infusion of the CCKB receptor agonist pentagastrin potentiates acoustic startle. Brain Res 1996; 733: 12932.

[20] Harro J, Vasar E. Evidence that CCKB receptors mediate the regulation of exploratory behavior in the rat. Eur $\mathrm{J}$ Pharmacol 1991; 193: 379-81.

[21] Bradwejn J, Koszycki D, Meterissian G. Cholecystokinin tetrapeptide induces panic attacks in patients with panic disorder. Can J Psychiatry 1990; 35: 83-5.

[22] Koszycki D, Zacharko RM, Bradwejn J. Influence of personality on behavioral response to cholecystokinin-tetrapeptide in patients with panic disorder. Psychiatry Res 1996; 62: 131-8

[23] van Megen HJGM, Westenberg HGM, den Boer JA, Kahn RS. The panic inducing properties of the cholecystokinin tetrapeptide CCK4 in patients with panic disorder. Eur Neuropsychopharmacol 1996; 6: $187-94$

[24] Gardner WN. The pathophysiology of hyperventilation disorders. Chest 1996; 109: 516-34.

[25] Lara N, Chrapko WE, Archer SL, Bellavance F, Mayers I, Le Melledo JM. Pulmonary and systemic nitric oxide measurements during CCK-5-induced panic attacks. Neuropsychopharmacology 2003; 28: 1840-5.

[26] Ley R. Panic attacks: Klein's false suffocation alarm, Taylor and Rachman's data, and Ley's dyspneic-fear theory. Arch Gen Psychiatry 1996; 53: 83

[27] Faravelli C. Life events preceding the onset of panic disorder. J Affect Disord 1985; 9: 103-5.

[28] Roy-Byrne PP, Geraci M, Uhde TW. Life events and the onset of panic disorder disorder. Am J Psychiatry 1986; 143(11): 1424-7.

[29] Roy-Byrne PP, Rubinow DR, Linnoila M. Relation between plasma prolactin and plasma homovanillic acid in normal subjects. Neuropsychobiology 1986; 16: 85-7.

[30] Roy-Byrne PP, Uhde TW, Post RM, Gallucci W, Chrousos GP, Gold PW. The corticotropin-releasing hormone stimulation test in patients with panic disorder. Am J Psychiatry 1986; 143(7): 896-9.

[31] Roy-Byrne PP, Uhde TW, Sack DA, Linnoila M, Post RM. Plasma HVA and anxiety in patients with panic disorder. Biol Psychiatry 1986; $21: 847-9$

[32] Scocco P, Barbieri I, Frank E. Interpersonal problem areas and onset of panic disorder. Psychopathology 2006; 40: 8-13.

[33] Servant D, Bailly D, Dewailly D, Beuscart R, Parquet PJ. Recent life stress and the corticotropin-releasing factor test in panic disorder. Anxiety 1993; 232: 209-10.

[34] Hokfelt T, Rehfeld JF, Skirboll LR, Ivemark B, Goldstein M, Markey K. Evidence for coexistence of dopamine and CCK in mesolimbic neurones. Nature 1980; 285: 476

[35] Studler JM, Reibaud M, Tramu G, Blanc G, Glowinski J, Tassin JP. Pharmacological study on the mixed CCK-8/DA meso-nucleus pathway: Evidence for the existence of storage sites containing the two neurotransmitters. Brain Res 1984; 298: 91

[36] Deutch AY, Tam S-Y, Roth RH. Footshock and conditioned stress increase 3,4-dihydroxyphenylacetic acid (DOPAC) in the ventral tegmental area but not substantia nigra. Brain Res 1985; 333: 1436.

[37] Harro J, Loftberg C, Rehfeld JF, Oreland L. Cholecystokinin peptides and receptors in the rat brain druing stress. Naunyn Schmiedebergs Arch Pharmacol 1996; 354: 59-66.

[38] Siegel RA, Duker EM, Pahnke U, Wuttke W. Stress-induced changes in cholecystokinin and substance $\mathrm{P}$ concentrations in discrete regions of the rat hypothalamus. Neuroendocrinology 1987; 46: 75-81.

[39] Pavlasevic S, Bednar I, Qureshi GA, Sodersten P. Brain cholecystokinin tetrapeptide levels are increased in a rat model of anxiety. Neuroreport 1993; 5: 225-8.

[40] Ferrarese C, Mennini T, Pecora N, et al. Diazepam binding inhibitor (DBI) increases after acute stress in rat. Neuropharmacology 1991; 30(12B): 1445-52.

[41] Nemeroff CB. New vistas in neuropeptide research in neuropsychiatry: Focus on corticotropin-releasing factor. Neuropsychopharmacology 1992; 6(2): 69-75.

[42] Roth RH, Tam S-Y, Ida Y, Yang J-X, Deutch AY. Stress and the mesocorticolimbic system. In: Kalivas PW, Nemeroff CB, eds. The
Mesocorticolimbic System. New York: New York Academy of Sciences 1988

[43] Wolpe J, Rowan VC. Panic disorder: A product of classical conditioning. Behav Res Ther 1988; 26(6): 441-50.

[44] Kalivas PW, Sorg BA, Hooks MS. The pharmacology and neural circuitry of sensitization to psychostimulants. Behav Pharmacol 1993; 4: 315-34.

[45] Post RM, Weiss SR. Sensitization, kindling, and carbamazepine: An update on their implications for the course of affective illness. Pharmacopsychiatra 1992; 25: 41-3.

[46] Lachuer J, Gaillet S, Barbagli B, Buda M, Tappaz M. Differential early time course activation of the brainstem catecholaminergic groups in response to various stresses. Neuroendocrinology 1991 53: 589-96.

[47] Sudo A, Miki K. Dissociation of catecholamine and corticosterone responses to different types of stress in rats. Ind Health 1993; 31(3): 101-11.

[48] Jones BC, Campbell AD, Radcliffe RA, Erwin VG. Psychomotor stimulant effect of cocaine is affected by genetic makeup and experimental history. Ann N Y Acad Sci 1992; 654: 456-8.

[49] Beatty WW, Holzer GA. Sex differences in stereotyped behavior in the rat. Pharmacol Biochem Behav 1978; 9: 777-83.

[50] Blanchard DC, Griebel G, Blanchard RJ. Gender bias in the preclinical psychopharmacology of anxiety: Male models for (predominantly) female disorders. J Psychopharmacol 1995; 9(2): 79-82.

[51] Camp DM, Robinson TE. Susceptibility to sensitization. I. Sex differences in the enduring effects of chronic D-amphetamine treatment on locomotion, stereotyped behavior and brain monoamines. Behav Brain Res 1988; 30: 55-68.

[52] Grilo CM, Becker DF, Fehon DC, Walker ML, Edell WS McGlashen TH. Gender differences in personality disorders in psychiatrically hospitalized adolecents. Am J Psychiatry 1996; 153(8): 1089-91.

[53] Heinsbroek RW, van Haaren F, Feenstra MGP, van Galen H, Boer G, van de Poll N. Sex differences in the effects of inescapable footshock on central catacholaminergic and serotonergic activity. Pharmacol Biochem Behav 1990; 37: 539-50.

[54] Robinson TE, Becker JB, Ramirez VD. Sex differences in amphetamine-elicited rotational behavior and the lateralization of striatal dopamine in rats. Brain Res Bull 1980; 5: 539-45.

[55] Robinson TE, Becker JB, Presty SK. Long-term facilitation of amphetamine induced rotational behavior and striatal dopamine release produced by a single exposure to amphetamine: sex differences. Brain Res 1982; 253: 231-41

[56] Wittchen HU, Essau CA. Epidemiology of panic disorder: progress and unresolved issues. J Psychiatr Res 1993; 27(Suppl 1): 47-68.

[57] Grillon C, Ameli R, Merikangas K, Woods SW, Davis M. Measuring the time course of anticipatory anxiety using the fearpotentiated startle reflex. Psychophysiology 1993; 30: 340-6.

[58] Kuribara H. Importance of post-drug environmental factors for induction of sensitization to the ambulation-increasing effects of methamphetamine and cocaine in mice. Psychopharmacology 1996; 126: 292-300

[59] Post RM. Intermittent versus continuous stimulation: Effect of time interval on the development of sensitization or tolerance. Life Sci 1980; 26: 1275-82.

[60] Schnur P, Espinoza M, Flores R. Context-specific sensitization to naloxone-precipitated withdrawal in hamsters: Effect of pimozide. Pharmacol Biochem Behav 1994; 48(3): 791-7.

[61] Stewart J, Vezina P. Conditioning and behavioral sensitization. In: Kalivas PW, Barnes CD, eds. Sensitization in the Nervous System. New York: Telford Press 1988.

[62] Vezina P, Giovino AA, Wise RA, Stewart J. Environment-specific cross-sensitization between the locomotor activating effects of morphine and amphetamine. Pharmacol Biochem Behav 1989; 32: 581-4.

[63] Antelman SM, Eichler AJ, Black CA, Kocan D. Interchangeability of stress and amphetamine in sensitization. Science 1980; 207(18): 329-31.

[64] Pierce RC, Kalivas PW. Amphetamine produces sensitized increases in locomotion and extracellular dopamine preferentially in the nucleus accumbens shell of rats administered repeated cocaine. J Pharmacol Exp Ther 1995; 275(2): 1019-29. 
[65] Fukamauchi F. Changes in cholecystokinin mRNA expression in methamphetamine induced behavioral sensitization. Neurochemistry Int 1996; 28(4): 391-4.

[66] Hurd YL, Lindefors N, Brodin E, et al. Amphetamine regulation of mesolimbic dopamine/cholecystokinin neurotransmission. Brain Res 1992; 578(317-326).

[67] Pratt JA, Brett RR. The benzodiazepine receptor inverse agonist FG 7142 induces cholecystokinin gene expression in rat brain. Neurosci Lett 1995; 184: 197-200.

[68] Pitchot W, Ansseau M, Moreno A, Hansenne M, von Frenckell R. Dopaminergic function in panic disorder: Comparison with major and minor depression. Biol Psychiatry 1992; 32: 1004-11.

[69] Brambilla F, Bellodi L, Perna G, Garberi A, Panerai A, Sacerdote P. Lymphocyte cholecystokinin concentrations in panic disorder. Am J Psychiatry 1993; 150: 1111-3.

[70] Lydiard RB, Ballenger JC, Laraia MT, Fossey MD, Beinfeld MC. CSF cholecystokinin concentrations in patients with panic disorder and in normal comparison subjects. Am J Psychiatry 1992; 149(5): 691-3.

[71] Yoshioka M, Matsumoto M, Togashi H, Saito H. Effect of conditioned fear stress on dopamine release in the rat prefrontal cortex. Neurosci Lett 1996; 209(3): 201-3.

[72] Kellner R, Wilson RM, Muldawar MD, Pathak D. Anxiety in schizophrenia. The responses to chlordiazepoxide in an intensive design study. Arch Gen Psychiatry 1975; 32(10): 1246-54.

[73] Menza M, Forman N, Sage J, Cody R. Psychiatric symptoms in Parkinson's disease: A comparison between patients with and without “on-off” symptoms. Biol Psychiatry 1993; 33: 682-4

[74] Rasmussen K. CCK, schizophrenia, and anxiety. CCK-B antagonists inhibit the activity of brain dopamine neurons. Ann N Y Acad Sci 1994; 713: 300-11.

[75] Stein MB, Heuser IJ, Juncos J, Uhde TW. Anxiety disorders in patients with Parkinson's disease. Am J Psychiatry 1990; 147(2): 217-20.

[76] Crawley JN, Corwin RL. Biological actions of cholecystokinin. Peptides 1994; 15(4): 731-55.

[77] Harro J, Vasar E, Bradwejn J. CCK in animal and human research on anxiety. TiPS $1993 ; 14: 244-9$.

[78] Davis M. Sensitization of the acoustic startle reflex by footshock. Behav Neurol 1989; 103: 495-503.

[79] Inoue T, Tsuchiya K, Koyama T. Regional changes in dopamine and serotonin activation with various intensity of physical and psychological stress in the rat brain. Pharmacol Biochem Behav 1994; 49(4): 911-20.

[80] Servatius R, Ottenweller JE, Natelson BH. Delayed startle sensitization distinguishes rats exposed to one or three stress sessions: Further evidence toward an animal model of PTSD. Biol Psychiatry 1995; 38: 539-46.

[81] Coco ML, Kuhn CM, Ely TD, Kilts CD. Selective activation of mesoamygdaloid dopamine neurons by conditioned stress: Attenuation by diazepam. Brain Res 1992; 590: 39-47.

[82] Ida Y, Tsuda A, Sueyoshi K, Shirao I, Tanaka M. Blockade by diazepam of conditioned fear-induced activation of rat mesoprefrontal dopamine neurons. Pharmacol Biochem Behav 1988; 33: 477-9.

[83] Bremner JD, Krystal JH, Southwick SM, Charney DS. Noradrenergic mechanisms in stress and anxiety: I. Preclinical studies. Synapse 1996; 23: 28-38.

[84] Charney DS, Innis RB, Duman RS, Woods SW, Heninger GR. Platelet alpha-2-receptor binding and adenylate cyclase activity in panic disorder. Psychopharmacology 1989; 98: 102-7.

[85] Charney DS, Heninger GR. Abnormal regulation of noradrenergic function in panic disorder: Effects of clonidine in healthy subjects and patients with agoraphobia and panic disorder. Arch Gen Psychiatry 1986; 43: 1042-54.

[86] Guthrie SK, Grunhaus L, Pande A, Hariharan M. Noradrenergic response to intravenous yohimbine in patients with depression and comorbitity of depression and panic. Biol Psychiatry 1993; 34: 558-61.

[87] Hoehn-Saric R. Neurotransmitters in anxiety. Arch Gen Psychiatry 1982; 39: 735-42.

[88] Nutt DJ. Altered central $\alpha 2$-adrenoceptor sensitivity in panic disorder. Arch Gen Psychiatry 1989; 46: 165-9.

[89] Nutt DJ. The pharmacology of human anxiety. Pharmacol Ther 1990; 47: 233-63.
[90] Uhde TW, Stein MB, Vittone BJ, et al. Behavioral and physiological effects of short-term and long-term administration of clonidine in panic disorder. Arch Gen Psychiatry 1989; 46: 170-7.

[91] Pitchot W, Hansenne M, Moreno A, von Frenckell R, Ansseau M. Psychopathological correlates of dopaminergic disturbances in major depression. Neuropsychobiology 1990; 24: 169-72.

[92] Cole BJ, Hillmann M, Seidelmann D, Klewer M, Jones GH. Effects of benzodiazepine receptor partial inverse agonists in the elevated plus maze test of anxiety in the rat. Psychopharmacology 1995; 121: 118-26.

[93] D'Aquila PS, Brain P, Willner P. Effects of chronic mild stress on performance in behavioral tests relevant to anxiety and depression. Physiol Behav 1994; 56(5): 861-7.

[94] McBlane JW, Handley SL. Effects of two stressors on behavior in the elevated $\mathrm{x}$-maze: preliminary investigation of their interaction with 8-OH-DPAT. Psychopharmacology 1994; 116: 173-82.

[95] Berg WK, Davis M. Diazepam blocks fear-enhanced startle elicited electrically from the brain stem. Physiol Behav 1984; 32(2): 333-6.

[96] Claustre Y, Rivy JP, Dennis T, Scatton B. Pharmacological studies on stress-induced increase in frontal cortical dopamine metabolism in the rat. The J Pharmacol Exp Ther 1986; 238(2): 317-26.

[97] Fadda F, Argiolas A, Melis MR, Tissari AH, Onali PL, Gessa GL. Stress induced increase in 3,4-dihydroxyphenylacetic acid (DOPAC) levels in the cerebral cortex and in nucleus accumbens: Reversal by diazepam. Life Sci 1978; 23: 2219-24.

[98] Lane JD. Neurochemical changes associated with the action of acute administration of diazepam in reversing the behavioral paradigm conditioned emotional response (CER). Neurochem Res 1992; 17(5): 497-507.

[99] Eriksson E, Westberg P, Alling C, Thuresson K, Modigh K. Cerebrospinal fluid levels of monoamine metabolites in panic disorder. Psychiatry Res 1991; 36: 243-51.

[100] Johnson MR, Lydiard RB, Zealberg JJ, Fossey MD, Ballenger JC. Plasma and CSF HVA levels in panic patients with comorbid social phobia. Biol Psychiatry 1994; 36: 426-7.

[101] Charney DS, Woods SW, Nagy LM, Southwick SM, Krystal JH Heninger GR. Noradrenergic function in panic disorder. J Clin Psychiatry 1990; 51(12, Suppl A): 5-11.

[102] Lepola U, Jolkkonen J, Rimon R, Riekkinen P. Long-term effects of alprazolam and imipramine on cerebral spinal fluid monoamine metabolites and neuropeptides in panic disorder. Neuropsychobiology 1989; 21: 182-6.

[103] Zemishlany Z, Davidson M. Lack of effect of laboratory-provoked anxiety on homovanillic acid concentration in normal subjects. Biol Psychiatry 1996; 40: 247-52.

[104] Leyton M, Belanger C, Martial J, et al. Cardiovascular, neuroendocrine, and monoaminergic responses to psychological stressors: possible differences between remitted panic disorder patients and healthy controls. Biol Psychiatry 1996; 40(5): 353-60.

[105] Eichler AJ, Antelman SM. Sensitization to amphetamine and stress may involve nucleus accumbens and medial frontal cortex. Brain Res 1979; 176: 412-6.

[106] Kalivas PW, Stewart J. Dopamine transmission in the initiation and expression of drug- and stress-induced sensitization of motor activity. Brain Res Rev 1991; 16: 223-44.

[107] Agid Y, Javoy-Agid F. Peptides and Parkinson's disease. TiNs 1985; 8(1): 30-5.

[108] Bruno G, Ruggieri S, Chase TN, Bakker K, Tamminga CA. Caerulein treatment of Parkinson's disease. Clin Neuropharmaco 1985; 8(3): 266-70.

[109] Fernandez A, de Ceballos ML, Jenner P, Marsden CD. Striatal neuropeptide levels in Parkinson's disease patients. Neurosci Lett 1992; 145: 171-4.

[110] Kontur PJ, Al-Tikriti M, Innis RB, Roth RH. Postmortem stability of monoamines, their metabolites, and receptor binding in rat brain regions. J Neurochem 1994; 62(1): 282-90.

[111] White RF, Au R, Durso R, Moss MB. Neuropsychological function in Parkinson's disease. In: White RF, ed. Clinical Syndromes in Adult Neuropsychology: The Practitioner's Handbook. The Netherlands: Elsevier Science 1992: 253-86.

[112] Piolti R, Appollonio I, Cocco E, et al. Treatment of Parkinson's disease with proglumide, a CCK antagonist. Neurology 1991; 41: 749-50.

[113] Mahurin RK, Feher EP, Nance ML, Levy JK, Pirozzolo FJ. Cognition in Parkinson's disease and related disorders. In: Parks RW, Wilson RS, Zec RF, Eds. Neuropsychology of Alzheimer's 
Disease and Other Dementias. New York: Oxford University Press 1993.

[114] Pirozzolo FJ, Swihart AA, Rey G, Jankovic J, Mortimer JA. Cognitive impairments associated with Parkinson's disease and other Mov Disord. In: Jankovic J, Tolosa E, eds. Parkinson's Disease and Mov Disord. Baltimore-Munich: Urban \& Schwarzenberg 1988.

[115] Rafal RD, Posner MI, Walker JA, Friedrich FJ. Cognition and the basal ganglia. Brain 1984; 107: 1083-94.

[116] Taylor AE, Saint-Cyr JA, Lang AE. Frontal lobe dysfunction in Parkinson's disease. Brain 1986; 109: 845-83.

[117] Vogel HP. Symptoms of depression in Parkinson's Disease. Pharmacopsychiatra 1982; 15(6): 192-6.

[118] Riley R, Kahn RJ, McNair DM, Frankenthaler LM. The spectrum of levodopa-related fluctuations in Parkinson's disease. Neurology 1986; 43: 1459-64.

[119] Lezak MD. Neuropsychological Assessment. New York: Oxford University Press 1983

[120] Menza M, Robertson-Hoffman D, Bonapace A. Parkinson's disease and anxiety: Comorbidity with depression. Biol Psychiatry 1993; 34: 465-70.

[121] Siemers ER, Shekhar A, Quaid K, Dickson H. Anxiety and motor performance in Parkinson's disease. Mov Disord 1993; 8(4): 501-6.

[122] Vazquez A, Jimenez-Jimenez FJ, Garcia-Ruiz P, Garcia-Urra D. Panic attacks in Parkinson's disease: A long-term complication of levodopa therapy. Acta Psychiatr Scand 1993; 87(1): 14-8.

[123] Maricle RA, Nutt JG, Valentine RJ, Carter JH. Dose-response relationship of levodopa with mood and anxiety in fluctuating Parkinson's disease: a double-blind, placebo-controlled study. Neurology 1995; 45(9): 1757-60.

[124] Factor SA, Molho ES, Podskalny GD, Brown D. Parkinson's disease: Drug induced psychiatric states. Adv Neurol 1995; 65: 115-38.

[125] Kulkarni J, Horne M, Butler E, Keks N, Copolov D. Psychotic symptoms resulting from intraventricular infusion of dopamine in Parkinson's disease. Biol Psychiatry 1992; 31: 1225-7.

[126] Oyebode JR, Barker WA, Blessed G, Dick DJ, Britton PG. Cognitive functioning in Parkinson's disease: In relation to prevalence of dementia and psychiatric diagnosis. Br J Psychiatry 1986; 149: 720-5

[127] Carey RJ, Dai H, Huston JP, Pinheiro-Carrera M, Schwarting RK, Tomaz C. L-DOPA metabolism in cortical and striatal tissues in an animal model of Parkinsonism. Brain Res Bull 1995; 37(3): 295-9.

[128] Rich SS, Friedman JH, Ott BR. Risperidone versus clozapine in the treatment of psychosis in six patients with Parkinson's disease and other akinetic-rigid syndromes. J Clin Psychiatry 1995; 56(12): 556-9.

[129] Schmidt NB, Lerew DR, Trakowski JH. Body vigilance in panic disorder: Evaluating attention to bodily perturbations. J Consult Clin Psychol 1997; 65(2): 214-20.

[130] Chung CK, Remington ND, Suh BY. Estrogen replacement therapy may reduce panic symptoms. J Clin Psychiatry 1995; 56(11): 533.

[131] Price WA, Heil D. Estrogen-induced panic attacks. Psychosomatics 1988; 29(4): 433-5

[132] Bless EP, McGinnis KA, Mitchell AL, Hartwell A, Mitchell JB. The effects of gonadal steroids on brain stimulation reward in female rats. Behav Brain Res 1997; 82: 235-44

[133] Beitman BD, Mukerji V, Russell JL, M G. Panic disorder in cardiology patients: A review of the Missouri panic/cardiology project. J Psychiatr Res 1993; 27(Suppl 1): 35-46.

[134] Andreoli A, Keller SE, Rabaeus M, Zaugg L, Garrone G, Taban C. Immunity, major depression, and panic disorder comorbidity. Biol Psychiatry 1992; 31: 896-908.

[135] Breier A, Charney D, Heninger G. Major depression in patients with agoraphobia and panic disorder. Arch Gen Psychiatry 1984; 41: 1129-35

[136] Grunhaus L, Harel Y, Krugler T, Pande A, Haskett RF. Major depressive disorder and panic disorder. Clin Neuropharmacol 1988; 11: 454-61.

[137] Keller MB, Hanks DL. Course and outcome in panic disorder. Prog Neuro-Psychopharmacol Biol Psychiatry 1993; 17: 551-70.

[138] Laberge B, Gauthier J, Cote G, Plamondon J, Cormier HJ. The treatment of coexisting panic and depression: A review of the literature. J Anxiety Disord 1992; 6: 169-80.
[139] Leckman JF, Weissman MM, Merikangas KR, Pauls DL, Prusoff BA. Panic disorder and major depression. Arch Gen Psychiatry 1983; 40: 1055-60.

[140] Maier W, Minges J, Lichtermann D. The familial relationship between panic disorder and unipolar depression. J Psychiatr Res 1995; 29(5): 375-88

[141] Raskin M, Peeke H, Dickman W, Pinsker H. Panic and generalized anxiety disorders: Developmental antecedents and precipitants. Arch Gen Psychiatry 1982; 39: 687-9.

[142] Reich J, Warshaw M, Peterson LG, et al. Comorbidity of panic and major depressive disorder. J Psychiatr Res 1993; 27(Suppl 1): 2333

[143] Leenders KL, Palmer AJ, Quinn N, et al. Brain dopamine metabolosim in patients with Parkinson's disease measured with positron emission tomography. J Neurol Neurosurg Psychiatry 1986; 49(8): 853-60.

[144] Marie RM, Barrie L, Rioux P, Allain P, Lechevalier B, Baron JC. PET imaging of neocortical monoaminergic terminals in Parkinson's disease. J Neural Transm 1995; 9(1): 55-71.

[145] Uhl GR, Hedreen JC, Price DL. Parkinson's disease: loss of neurons from the ventral tegmental area contralateral to the therapeutic surgical lesions. Neurology 1985; 35(8): 1215-8.

[146] Studler JM, Javoy-Agid F, Cesselin F, Legrand JC, Agid Y. CCK-8 immuno-reactivity distribution in human brain: Selective decrease in the substantia nigra from parkinsonian patients. Brain Res 1982; 243: 176-9.

[147] Boyce S, Rupniak NMJ, Steventon M, Iverson SD. CCK-8S inhibits 1-dopa-induced dyskinesias in parkinsonian squirrel monkeys. Neurology 1990; 40: 717-8.

[148] Boyce S, Rupniak NMJ, Tye S, Steventon M, Iverson SD Modulatory role for CCK-B antagonists in Parkinson's disease. Clin Neuropharmacol 1990; 13(4): 339-47.

[149] Brog JS, Beinfeld MC. Cholecystokinin release from the rat caudate-putamen, cortex and hippocampus is increased by activation of the D1 dopamine receptor. J Pharmacol Exp Ther 1992; 260(1): 343-8.

[150] Carey RJ. Chronic L-dopa treatment in the unilateral 6-OHDA rat: Evidence for behavioral sensitization. Brain Res 1991; 568: 205 14

[151] Taylor MD, DeCeballos ML, Rose S, Jenner P, Marsden CD. Effects of unilateral 6-hydroxyphenylalanine treatment on peptidergic systems in rat basal ganglia. Eur J Pharmacol 1992; 219: 183-92.

[152] Harro J, Marcussen J, Oreland L. Alterations in brain cholecystokinin receptors in suicide victims. Eur $\mathbf{J}$ Pharmacol 1992; 2: 57-63.

[153] Philipp E, Wilckens T, Friess E, Platte P, Pirke K-M Cholecystokinin, gastrin and stress hormone responses in marathon runners. Peptides 1992; 13: 125-8.

[154] Brodin K, Ogren SV, Brodin E. Effects of sequential removal of rats from a group cage, and of individual housing of rats, on substance $\mathrm{P}$, cholecystokinin and somatostatin levels in the periaqueductal grey and limbic regions. Neuropeptides 1994; 26: 253-60.

[155] Rosen A, Brodin K, Eneroth P, Brodin E. Short-term restraint stress and s.c. saline injection alter the tissue levels of substance $\mathrm{P}$ and cholecystokinin in the peri-aqueductal grey and limbic regions of the rat brain. Acta Psychiatr Scand 1992; 146: 341-8.

[156] Azorin JM. Long-term treatment of mood disorders in schizophrenia. Acta Psychiatr Scand 1995; 388(Suppl): 20-3.

[157] Craig TJ, Richardson MA, Pass R, Bregman Z. Measurement of mood and affect in schizophrenic inpatients. Am J Psychiatry 1985; 132(11): 1272-7.

[158] Donlon PT, Rada RT, Arora KK. Depression and the reintegration phase of acute schizophrenia. Am J Psychiatry 1976; 133(11) 1265-8.

[159] Silverstein ML, Mavrolefteros G, Close D. BPRS syndrome scales during the course of an episode of psychiatric illness. J Clin Psychol 1997; 53(5): 455-8.

[160] Lysaker PH, Bell MD, Bioty SM, Zito WS. The frequency of associations between positive and negative symptoms and dysphoria in schizophrenia. Compr Psychiatry 1995; 36(2): 113-7.

[161] Penn DL, Hope DA, Spaulding W, Kucera J. Social anxiety in schizophrenia. Schizophr Res 1994; 11(3): 277-84. 
[162] Shaw K, McFarlane A, Bookless C. The phenomenology of traumatic reactions to psychotic illness. J Nerv Ment Dis 1997; 185(7): 434-41.

[163] Butler RW, Mueser KT, Sprock J, Braff DL. Positive symptoms of psychosis in posttraumatic stress disorder. Biol Psychiatry 1996; 39: 839-44.

[164] Day R. Life events and schizophrenia: The "triggering" hypothesis. Acta Psychiatr Scand 1981; 64: 97-122.

[165] Docherty NM. Affective reactivity of symptoms as a process discriminator in schizophrenia. J Nerv Ment Dis 1996; 184(9): 53541.

[166] Dohrenwend BP, Egri G. Recent stressful life events and episodes of schizophrenia. Schizophr Bull 1981; 7(1): 12-23

[167] Fowles DC. Schizophrenia: Diathesis-stress revisited. Annu Rev Psychol 1992; 43: 303-36.

[168] Harrow M, Yonan CA, Sands JR, Marengo J. Depression in schizophrenia: Are neuroleptics, akinesia, or anhedonia involved? Schizophr Bull 1994; 20(2): 327-38.

[169] Hatfield AB. Patients' accounts of stress and coping in schizophrenia. Hospital Community Psychiatry 1989; 40(11): 1141-5.

[170] Lukoff D, Snyder K, Ventura J, Nuechterlein KH. Life events, familial stress, and coping in the developmental course of schizophrenia. Schizophr Bull 1984; 10(2): 258-92.

[171] Spring B. Stress and schizophrenia: Some definitional issues. Schizophr Bull 1981; 7(1): 24-33.

[172] Schwartz CC, Myers JK. Life events and schizophrenia. II. Impact of life events and symptom configuration. Arch Gen Psychiatry 1977; 34(10): 1240-5.

[173] Bolino F, Di Michele V, Di Cicco L, Manna V, Daneluzzo E, Casacchia M. Sensorimotor gating and habituation evoked by electro-cutaneous stimulation in schizophrenia. Biol Psychiatry 1994; 36(10): 670-9

[174] Patterson T, Spohn HE, Bogia DP, Hayes K. Thought disorder in schizophrenia: Cognitive and neuroscience approaches. Schizophr Bull 1986; 12(3): 460-72.

[175] Argyle N. Panic attacks in chronic schizophrenia. Br J Psychiatry 1990; 157: 430-3.

[176] Kahn JP, Krusin RE, Klein DF. Schizophrenia, panic anxiety and alprazolam. Am J Psychiatry 1987; 144: 527-8.

[177] Kahn JP, Puertollano MA, Schane MD, Klein DF. Adjunctive alprazolam for schizophrenia with panic anxiety: Clinical observation and pathogenetic implications. Am J Psychiatry 1988; 145(6): 742-4

[178] Sanderg L, Siris SG. Panic disorder in schizophrenia. J Nerv Ment Dis 1987 ; 175(10): 627-8.

[179] Aronson TA, Logue CM. Phenomenology of panic attacks: A descriptive study of panic disorder patients' self reports. J Clin Psychiatry 1988; 49: 8-13.

[180] Lewine RJ, Walker EF, Shurett R, Caudle J, Haden C. Sex differences in neuropsychological functioning among schizophrenic patients. Am J Psychiatry 1996; 153(9): 1178-84.

[181] Simon H, Scatton B, LeMoal M. Dopaminergic A10 neurons are involved in cognitive functions. Nature 1980; 286(5769): 150-1.

[182] Heila H, Isometsa ET, Henriksson MM, Heikkinen ME, Marttunen MJ, Lonnqvist JK. Suicide and schizophrenia: A nationwide psychological autopsy study on age- and sex-specific clinical characteristics of 92 suicide victims with schizophrenia. Am J Physiol 1997; 154(9): 1235-42.

[183] Clum GA, Surls R. A meta-analysis of treatments for panic disorder. J Consult Clin Psychol 1993; 61(2): 317-26.

[184] Ciccone PE, Bellettirie GF. A patient with panic disorder eventuating in psychosis: Nosologic implications. Psychiatr J Univ Ott 1989; 14(3): 478-80.

[185] Heun R, Maier W. Relation of schizophrenia and panic disorder: Evidence form a controlled family study. Am J Med Genet 1995; 60: 127-32.

[186] Neenan P, Felkner J, Reich J. Schizoid personality traits developing secondary to panic disorder. J Nerv Ment Dis 1986; 174(8): 483.

[187] Mackay AVP, Iversen LL, Rossor M, et al. Increased brain dopamine and dopamine receptors in schizophrenia. Arch Gen Psychiatry 1982; 39: 991-7.

[188] Comings D, Comings B, Muhleman D, et al. The dopamine D2 receptor locus as a modifying gene in neuropsychiatric disorders. JAMA 1991; 266(13): 1793-800.
[189] Schmauss C, Haroutunian V, Davis KL, Davidson M. Selective loss of dopamine D3-type receptor mRNA expression in parietal and motor cortices of patients with chronic schizophrenia. Proc Natl Acad Sci USA 1993; 90(19): 8942-6.

[190] Kapur S, Remington G, Jones C, et al. High levels of dopamine D2 receptor occupancy with low-dose haloperidol treatment: A PET study. Am J Psychiatry 1996; 153(7): 948-50.

[191] Busatto GF, Pilowsky LS, Costa DC, Ell PJ, Verhoeff NPLG, Kerwin RW. Dopamine $\mathrm{D}_{2}$ receptor blockade in vivo with the novel antipsychotics risperidone and remoxipride - an ${ }^{123}$ I-IBZM single photon emission tomography study. Psychopharmacology 1995; 117: 55-61.

[192] Minabe Y, Kadono Y, Kurachi M. A schizophrenic syndrome associated with a midbrain tegmental lesion. Biol Psychiatry 1990; 27: 661-3.

[193] Bench CJ, Dolan RJ, Friston KJ, Frackowiak RSJ. Positron emission tomography in the study of brain metabolism in psychiatric and neuropsychiatric disorders. Br J Psychiatry 1990; 157: 82-95.

[194] Cross AJ, Crow TJ, Ferrier IN, et al. Dopamine receptor changes in schizophrenia in relation to the disease process and movement disorder. J Neural Transm 1983; (Suppl 18): 265-72.

[195] Maas JW, Contreras SA, Miller AL, et al. Studies of catecholamine metabolism in schizophrenia/psychosis - I. Neuropsyhcopharmacology 1993a; 8(2): 97-109.

[196] Maas JW, Contreras SA, Miller AL, et al. Studies of catecholamine metabolism in schizophrenia/psychosis - II. Neuropsychopharmacol 1993b; 8(2): 111-6.

[197] Cotton JD, Usher M. A neural network model of stroop interference and facilitation effects in schizophrenia. Biol Psychiatry 1996; 39: 568.

[198] White FJ. Synaptic regulation of mesocorticolimbic dopamine neurons. Ann Rev Neurosci 1996; 19: 405-36.

[199] Williams GV, Goldman-Rakic PS. Modulation of memory fields by dopamine D1 receptors in prefrontal cortex. Nature 1995; 376: 5725.

[200] Angrist BM, Gershon S. The phenomenology of experimentally induced amphetamine psychosis - preliminary observations. Biol Psychiatry 1970; 2(2): 95-107.

[201] Ellison G. Stimulant-induced psychosis, the dopamine theory of schizophrenia, and the habenula. Brain Res Rev 1994; 19: 223-39.

[202] Flaum M, Schultz SK. When does amphetamine-induced psychosis become schizophrenia. Am J Psychiatry 1996; 153(6): 812-5.

[203] Leduc PA, Mittleman G. Schizophrenia and psychostimulant abuse: A review and re-analysis of clinical evidence. Psychophramacology 1995; 121: 407-27.

[204] Post RM, Weiss SR, Pert A. Cocaine-induced behavioral sensitization and kindling: Implications for the emergence of psychopathology and seizures. The Mesolimbic Dopamine System. New York: Annals of the New York Academy of Sciences 1988.

[205] Schatzberg AF, Posener JA, Rothschild AJ. The role of dopamine in psychotic depression. Clin Neuropharmacol 1995; 18(Suppl 1): S66-S73.

[206] Beinfeld MC, Garvey DL. Concentration of cholecystokinin in cerebrospinal fluid is decreased in psychosis: Relationship to symptoms and drug response. Prog Neuro-Psychopharmacol Biol Psychiatry 1991; 15(5): 601-9.

[207] Lotstra F, Verbanck PMP, Gilles C, Mendlewicz J, Vanderhaeghen J-J. Reduced cholecystokinin levels in cerebrospinal fluid of parkinsonian and schizophrenic patients. Ann N Y Acad Sci 1985; 448: 507-17.

[208] Nair NP, Lal S, Bloom DM. Cholecystokinin peptides, dopamine and schizophrenia-a review. Prog Neuro-Psychopharmacol Biol Psychiatry Clin N Am 1985; 9: 515-24.

[209] Wang RY, White FJ, Voigt MM. Cholecystokinin, dopamine and schizophrenia. TiPS 1984; 5(9): 436-8.

[210] Bourin M, Malinge M, Vasar E, Bradwejn J. Two faces of cholecystokinin: Anxiety and schizophrenia. Fund Clin Pharmacol 1996; 10: 116-26.

[211] Schalling M, Friberg K, Seroogy K, et al. Analysis of expression of cholecystokinin in dopamine cells in the ventral mesencephalon of several species and in humans with schizophrenia. Proc Natl Acad Sci USA 1990; 87: 8427-31.

[212] Farmery SM, Owen F, Poulter M, Crow TJ. Reduced high activity cholecystokinin binding in hippocampus and frontal cortex of schizophrenic patients. Life Sci 1985; 36: 473-7. 
[213] Ferrier IN, Roberts GW, Crow TJ, et al. Reduced cholecystokininlike and somatostatin-like immunoreactivity in limbic lobe is associated with negative symptoms in schizophrenia. Life Sci 1983; 33(5): 475-82.

[214] Ferrier IN, Crow TJ, Farmery SM, et al. Reduced cholecystokinin levels in the limbic lobe in schizophrenia. A marker for pathology underlying the defect state. Ann N Y Acad Sci 1985; 448: 495-506.

[215] Virgo L, Humphries C, Mortimer A, Barnes T, Hirsch S, de Belleroche J. Cholecystokinin messenger RNA deficit in frontal and temporal cerebral cortex in schizophrenia. Biol Psychiatry 1995; 37: 694-701.

[216] Davis KL, Davidson M, Mohs RC, et al. Plasma homovanillic acid concentration and the severity of schizophrenic illness. Science 1985; 227: 1601-2.

[217] Davis KL, Kahn RS, Ko G, Davidson M. Dopamine in schizophrenia: Review and reconceptualization. Am J Psychiatry 1991; 148(11): 1474-86.

[218] Brodin K, Ogren SV, Brodin E. Clomipramine and clonazepam increase cholecystokinin levels in rat ventral tegmental area and limbic regions. Eur J Pharmacol 1994; 263: 175-80.

[219] Frey P. Changes in cholecystokinin content in rat brain after subchronic treatment with neuroleptics. Ann N Y Acad Sci 1983; 95(1-2): 601-3.

[220] Chang RS, Lotti VJ, Martin GE, Chen TB. Increase in brain ${ }^{125} \mathrm{I}-$ cholecystokinin (CCK) receptor binding following chronic haloperidol treatment, intracisternal 6-hydroxydopamine or ventral tegmental lesions. Life Sci 1983; 32(8): 871-8.

[221] Suzuki T, Moroji T, Hori T, Baba A, Kawai N, Koizumi J. Autoradiographic localization of CCK-8 binding sites in the rat brain: effects of chronic methamphetamine administration on these sites. Biol Psychiatry 1993; 34: 781-90.

[222] Bachman KM, Modestin J. Neuroleptic-induced panic attacks in a patient with delusional depression. J Nerv Ment Dis 1987; 175(6): 373-5.

[223] Yeragani VK, Balon R, Pohl R. Schizophrenia, panic attacks, and antidepressants. Am J Psychiatry 1989; 146(2): 279.

[224] Forman SD, Bisette G, Tao J, Nemeroff CB, van Kammen DP. Cerebrospinal fluid corticotropin-releasing factor increases following haloperidol withdrawal in chronic schizophrenia. Schizophr Res 1994; 12(1): 43-51.

[225] Payeur R, Lydiard B, Ballenger JC, Laraia MT, Fossey MD, Zealberg J. CSF diazepam-binding inhibitor concentrations in panic disorder. Biol Psychiatry 1992; 32: 712-6.

[226] van Kammen DP, Guidotti A, Kelley ME, et al. CSF diazepam binding inhibitor and schizophrenia: clinical and biochemical relationships. Biol Psychiatry 1993; 34: 515-22.

[227] Bourin M, Bradwejn J, Nixon MK. Provacative agents and the biology of panic attacks. In: Hamon M, Ollat H, Thiebot M-H, eds. Anxiety: Neurobiology, Clinic and Therapeutic Perspectives. France: John Libby Eurotext, Ltd 1993: 257-92.

[228] Albus M. Cholecystokinin. Prog Neuro-Psychopharmacol Biol Psychiatry 1988; 12: S5-S21.

[229] Chase TN, Borane P, Bruno G, et al. Cholecystokinin-mediated synaptic function and the treatment of neuropsychiatric disease. Ann N Y Acad Sci 1985; 448: 553-61.

[230] Hommer DW, Pickar D, Crawley JN, Weingartner H, Paul SM. The effects of cholecystokinin-like peptides in schizophrenics and normal human subjects. Ann N Y Acad Sci 1985; 448: 542-51.

[231] Moroji T, Itoh K. Antipsychotic effects of ceruletide in chronic schizophrenia: an appraisal of the long-term, intermittent medication of ceruletide in chronic schizophrenia. Ann N Y Acad Sci $1985 ; 448$ : 518-33.

[232] Tamminga CA, Littman RL, Alphs LD, Chase TN, Thaker GK, Wagman AM. Neuronal cholecystokinin and schizophrenia: pathogenic and therapeutic studies. Psychopharmacology 1986; 88: 387-91.

[233] van Ree JM, Verhoeven WMA, Brouwer G, de Wied D. Ceruletide resembles antipsychotics in rats and schizophrenic patients. Neuropsychobiology 1984; 12: 4-8.

[234] Verhoeven WMA, Westenberg HGM, van Ree JM. A comparative study on the antipsychotic properties of desenkephalin- $\gamma$-endorphin and ceruletide in schizophrenic patients. Acta Psychiatr Scand 1986; 73(372-382): 372-82

[235] Vasar E, Peuranen E, Harro J, Lang A, Oreland L, Mannisto PT. Social isolation of rats increases the density of cholecystokinin receptors in the frontal cortex and abolishes the antiexploratory effect of caerulein. Naunyn Schmiedebergs Arch Pharmacol 1993; 348: 96-101.

[236] Bradwejn J, Koszycki D, Couetoux du Tertre A, et al. The panicogenic effects of cholecystokinin-tetrapeptide are antagonized by L-365,260, a central cholecystokinin receptor antagonist, in patients with panic disorder. Arch Gen Psychiatry 1995; 51: 48693.

[237] Rasmussen K, Stockton ME, Czachura JF, Howbert JJ. Cholecystokinin (CCK) and schizophrenia: the selective CCKB antagonist LY262691 decreases midbrain dopamine unit activity. Eur J Pharmacol 1991; 209: 135-8.

[238] Bogerts B, Hantsch J, Herzer M. A morphometric study of the dopamine-containing cell groups in the mesencephalon of normals, Parkinson patients, and schizophrenics. Biol Psychiatry 1983; 18(9): 951-69.

[239] Holcomb HH, Cascella NG, Thaker GK, Medoff DR, Dannals RF Tamminga CA. Functional sites of neuroleptic drug action in the human brain: PET/FDG studies with and without haloperidol. Am J Psychiatry 1996; 153(1): 41-9.

[240] Klemm E, Grunwald F, Kasper S, et al. [123]I IBZM SPECT for imaging of striatal D2 dopamine receptors in 56 schizophrenic patients taking varous neuroleptics. Am J Psychiatry 1996; 153(2): 183-90.

[241] Knable MB, Hyde TM, Murray AM, Herman MM, Kleinman JE. A postmortem study of frontal cortical dopamine D1 receptors in schizophrenics, psychiatric controls, and normal controls. Biol Psychiatry 1996; 40(12): 1191-9.

[242] Pedro BM, Pilowsky LS, Costa DC, et al. Stereotypy, schizophrenia and dopamine D2 receptor binding in the basal ganglia. Psychol Med 1994; 24(2): 423-9.

[243] Seeman P, Bzowej NH, Guan HC, et al. Human brain D1 and D2 dopamine receptors in schizophrenia, Alzheimer's, Parkinson's and Huntington's diseases. Neuropsychopharmacology 1987; 1(1): 515.

[244] MacNeil G, Sela Y, McIntosh J, Zacharko RM. Anxiogenic behavior in the light-dark paradigm following intraventricular administration of cholecystokinin-8S, restraint stress, or uncontrollable footshock in the CD-1 mouse. Pharmacol Biochem Behav 1997; 58(3): 737-46.

[245] van Dijken HH, Tilders FJH, Olivier B, Mos J. Effects of anxiolytic and antidepressant drugs on long-lasting behavioural deficits resulting from one short stress experience in male rats. Psychopharmacology 1992; 109(4): 395-402.

[246] Morgan CAI, Grillon C, Southwick SM, Davis M, Charney DS. Fear-potentiated startle in posttraumatic stress disorder. Biol Psychiatry $1995 ; 38(6): 378-85$

[247] Shaner A, Eth S. Can schizophrenia cause posttraumatic stress disorder? Am J Psychother 1989; 43(4): 588-97.

[248] Safadi G. Relationship of panic disorder to posttraumatic stress disorder. Arch Gen Psychiatry 1995; 52: 76-7.

[249] Southwick SM, Krystal JH, Charney DS. Reply to "Safadi, G. (1995). Relationship of panic disorder to posttraumatic stress disorder." Arch Gen Psychiatry 1995; 52: 77-8.

[250] Cook EWI, Davis TL, Hawk LW, Spence EL, Gauthier CH Fearfulness and startle potentiation during aversive visual stimuli. Psychopharmacology 1992; 29(6): 633-45.

[251] Grillon C, Ameli R, Goddard A, Woods SW, Davis M. Measuring the time course of anticipatory anxiety using the fear-potentiated startle reflex. Psychophysiology 1993; 30: 340-6.

[252] Soltis RP, Cook JC, Gregg AE, Sanders BJ. Interaction of GABA and excitatory amino acids in the basolateral amygdala: role in cardiovascular regulation. J Neurosci 1997; 17(23): 9367-74.

[253] Chen X, Kombian SB, Pittman QJ. Dopamine depresses excitatory synaptic transmission in the rat parabrachial nucleus in vitro. SfN Abstracts 1997; 23(2): 1211

[254] Oades RD. Search strategies on a hole-board are impaired in rats with ventral tegmental damage: Animal models for tests of thought disorder. Biol Psychiatry 1982; 17: 243-58.

[255] Abelson JL, Curtis GC. Hypothalamic-pituitary-adrenal axis activity in panic disorder: Prediction of long-term outcome by pretreatment cortisol levels. Am J Psychiatry 1996; 153(1): 69-73.

[256] Kathol RG, Noyes R, Lopez A. Similarities in hypothalamicpituitary-adrenal axis activity between patients with panic disorder and those experiencing external stress. Psychiatry Clin N Am 1988; 11(2): 335-48. 
[257] Harro J, Oreland L. Age-related differences of cholecystokinin receptor binding in the rat brain. Prog Neuro-Psychopharmacol Biol Psychiatry 1992; 16: 369-75.

[258] Garnefski N, van Egmond M, Straatman A. The influence of early and recent life stress on severity of depression. Acta Psychiatr Scand 1990; 81(3): 295-301.

[259] Manfro GG, Otto MW, McArdle ET, Worthington JJI, Rosenbaum JF, Pollack MH. Relationship of antecedent stressful life events to childhood and family history of anxiety and the course of panic disorder. J Affect Disord 1996; 41(2): 135-9.

[260] Shear KM. Factors in the etiology and pathogenesis of panic disorder: Revisiting the attachment-separation paradigm. Am J Psychiatry 1996; 153(7): 125-36.

[261] Whitehead WE, Crowell MD, Heller BR, Robinson JC, Schuster MM, Horn S. Modeling and reinforcement of the sick role during childhood predicts adult illness behavior. Psychosomatic Med 1994; 56(6): 541-50.

[262] Baum KM, Walker EF. Childhood behavioral precursors of adult symptom dimensions in schizophrenia. Schizophr Res 1995; 16(2): 111-20.

[263] Bentsen H, Boye B, Munkvold OG, et al. Emotional overinvolvement in parents of patients with schizophrenia or related psychosis: Demographic and clinical predictors. $\mathrm{Br} \mathrm{J}$ Psychiatry 1996; 169(5): 622-30.

[264] Rosenblum LA, Paully GS. The effects of varying environmental demands on maternal and infant behavior. Child Dev 1984; 55(1): 305-14.

[265] Coplan JD, Andrews MW, Rosenblum LA, et al. Persistant elevations of cerebrospinal fluid concentrations of corticotropinreleasing factor in adult nonhuman primates exposed to early-life stressors: Implications for the pathophysiology of mood and anxiety disorders. Proc Natl Acad Sci USA 1996; 93: 1619-23.

[266] Tiihonen J, Kuikka J, Bergstrom K, Lepola U, Koponen H, Leinonen E. Dopamine reuptake site densities in patients with social phobia. Am J Psychiatry 1997; 154(2): 239-42.

[267] Crawley JN, Stievers JA, Blumstein LK, Paul SM. Cholecystokinin potentiates dopamine-mediated behaviors: Evidence for modulation specific to a site of coexistence. J Neurosci 1985; 5: 1972-83.

[268] Emson PC, Lee CM, Rehfeld JF. Cholecystokinin octapeptide: Vesicular localization and calcium dependent release from rat brain in vitro. Life Sci 1980; 26: 2157-63.

[269] Hokfelt T, Skirboll LR, Everitt B, et al. Distribution of cholecystokinin-like immunoreactivity in the nervous system. Coexistence with classical neurotransmitters and other peptides. Ann N Y Acad Sci 1985: 255-73.

[270] Hokfelt T, Tsuruo Y, Meister B, Melander T, Schalling M, Everitt B. Localization of neuroactive substances in the hypothalamus with special reference to coexistence of messenger molecules. Adv Exp Med Biol 1987; 219: 21-45

[271] Lindefors N, Linden A, Brene S, Sedvall G, Persson H. CCK peptides and mRNA in the human brain. Prog Neurobiol 1993; 40: 671-90.

[272] Zanoveli JM, Netto CF, Guimaraes FS, Zangrossi H. Systemic and intra-dorsal periaqueductal gray injections of cholecystokinin sulfated octapeptide (CCK-8S) induce a panic-like response in rats submitted to the elevated T-maze. Peptides 2004; 25: 1935-41.

[273] Hokfelt T, Skirboll LR, Rehfeld JF, Goldstein M, Markey K, Dann O. A subpopulation of mesencephalic dopamine neurons projecting to limbic areas contains a cholecystokinin-like peptide: Evidence from immunohistochemistry combined with retrograde tracing. Neuroscience 1980; 5: 2093.

[274] Mezey E, Reisine TD, Skirboll L, Beinfeld M, Kiss JZ. Cholecystokinin in the medial parvocellular subdivision of the paraventricular nucleus. Coexistence with corticotropin-releasing hormone. Ann N Y Acad Sci 1985; 448: 152-6.

[275] Vanderhaeghen JJ, Lotstra F, DeMay J, Gilles C. Immunohistochemical localization of cholecystokinin- and gastrinlike peptides in the brain and hypophysis of the rat. Proc Natl Acad Sci USA 1980; 77: 1190-4.

[276] Skirboll L, Hokfelt T, Rehfeld J, Cuello AC, Dockray G. Coexistence of substance P- and cholecystokinin-like immunoreactivity in neurons of the mesencephalic periaqueductal central gray. Neurosci Lett 1982; 28: 35-9.

[277] Hendry SHC, Jones EG, DeFelipe J, Schmechel D, Brandon C, Emson PC. Neuropeptide-containing neurons of the cerebral cortex are also GABAergic. Proc Natl Acad Sci USA 1984; 81: 6526-30.
[278] Somogyi P, Hodgson AJ, Smith AD, Nunzi MG, Gorio A, Wu J-Y Different populations of GABAergic neurons in the visual cortex and hippocampus of cat contain somatostatin- or cholecystokininimmunoreactive material. J Neurosci 1984; 4: 2590-603.

[279] Gall C, Lautervorn J, Burks D, Seroogy K. Colocalization of enkephalin and cholecystokinin in discrete areas of rat brain. Brain Res 1987; 403: 403-8.

[280] Hebb ALO, Poulin JF, Roach SP, Zacharko RM, Drolet G. Cholecystokinin and endogenous opioid peptides: Interactive influence on pain, cognition, and emotion. Prog NeuroPsychopharmacol Biol Psychiatry 2005; 29(8): 1225-38.

[281] Hebb ALO, Laforest S, Drolet G. Endogenous opioids, stress and psychopathology. In: Steckler T, Kalin NH, Reul JMHM, eds. Handbook of Stress and the Brain: Elsevier 2005: 561-83.

[282] Baber NS, Dourish CT, Hill DR. The role of CCK, caerulein, and CCK antagonists in nocioception. Pain 1989; 39: 307-28.

[283] Harro J, Oreland L. Cholecystokinin receptors and memory: A radial maze study. Pharmacol Biochem Behav 1993; 44: 509-17.

[284] Gibbs J, Young RC, Smith GP. Cholecystokinin decreases food intake in rats. J Compreh Physiol Psychol 1973; 84: 488-95.

[285] Smith GP, Gibbs J. The development and proof of the CCK hypothesis of satiety. In: Dourish CT, Cooper SD, Iversen LL, eds. Multiple Cholecystokinin Receptors in the CNS: Oxford University Press 1992: 166-82.

[286] Ulibarri C, Micevych PE. Role of perinatal estrogens in sexual differentiation of the inhibition of lordosis by exogenous cholecystokinin. Physiol Behav 1993; 54: 95-100.

[287] Bradwejn J, de Montigny C. Benzodiazepines antagonize cholecystokinin-induced activation of rat hippocampal neurones. Nature 1984; 312(5992): 363-4.

[288] Hill DR, Campbell NJ, Shaw TM, Soodruff GN. Autoradiographic localization and biochemical characterization of peripheral type CCK receptors in rat CNS using highly selective non-peptide CCK antagonists. J Neurosci 1987; 7: 2967-77.

[289] Honda T, Wada E, Battey JF, Wank SA. Differential gene expression of CCKA and CCKB receptors in the rat brain. Mol Cell Neurosci 1993; 4: 143-54.

[290] Moran TH, McHugh PR. CCKA receptors. In: Bjorklund A, Hokfelt T, Kuher MJ, eds. Handbook of Chemical Neuroanatomy, 9: Neuropeptides in the CNS, Part II. New York: Elsevier Science Publishers 1990.

[291] Dourish CT, Ruckert AS, Tattersall FD, Iverson SD. Evidence that decreased feeding induced by systemic injection of cholecystokinin is mediated by CCK-A receptors. Eur J Pharmacol 1989; 173: 2334.

[292] Burazin TC, Gundlach AL. Rapid but transient increases in cholecystokinin mRNA levels in cerebral cortex following amygdaloid-kindled seizures in the rat. Neurosci Lett 1996; 209(1): 65-8.

[293] Kobayashi S, Ohta M, Miyasaka K, Funakoshi A. Decrease in exploratory behavior in naturally occurring cholecystokinin (CCK)A receptor gene knockout rats. Neurosci Lett 1996; 214: 61-4.

[294] Hirosue Y, Inui A, Miura M, et al. Effects of CCK antagonists on CCK-induced suppression of locomotor activity in mice. Peptides 1992; 13: 155-7.

[295] Wunderlich GR, DeSousa NJ, Vaccarino FJ. Microinjection of PD140,548 , a CCKA antagonist, into the caudal nucleus accumbens attenuates the locomotor response to amphetamine in amphetamine-sensitized animals. SfN Abstracts 1997; 23(2): 1621.

[296] Josselyn SA, Franco VP, Vaccarino FJ. Devazepine, a CCKA antagonist, impairs the acquisition of conditioned reward and conditioned activity. Psychopharmacology 1996; 123(2): 131-43.

[297] Branchereau P, Bohme J, Champagnat MP, et al. Cholecystokinin $\mathrm{A}$ and cholecystokinin $\mathrm{B}$ receptors in neurons of the brainstem solitary complex of the rat: Pharmacological identification. J Pharmacol Exp Ther 1992; 260: 1433-40.

[298] Durieux C, Pelaprat D, Charpentier B, Morgat J-L, Roques BP. Characterization of $[3 \mathrm{H}] \mathrm{CCK} 4$ binding sites in mouse and rat brain. Neuropeptides 1988; 12: 141-8.

[299] Horinouchi Y, Akiyoshi J, Nagata A, et al. Reduced anxious behavior in mice lacking the CCK2 receptor gene. Eur Neuropsychopharmacol 2004; 14: 157-61.

[300] Raud S, Runkorg K, Veraksits A, et al. Targeted mutation of CCK2 receptor gene modifies the behavioural effects of diazepam in female mice. Psychopharmacology (Berl) 2003; 168: 417-25. 
[301] Johnson MR, Rodgers RJ. Ethological analysis of cholecystokinin (CCKA and CCKB) receptor ligands in the elevated plus-maze test of anxiety in mice. Psychopharmacology 1996; 124(4): 355-64

[302] Netto CF, Guimaraes FS. Anxiogenic effect of cholecystokinin in the dorsal periaqueductal gray. Neuropsychopharmacology 2004; 29: 101-7.

[303] de Montigny C. Cholecystokinin tetrapeptide induces panic-like attacks in healthy volunteers. Arch Gen Psychiatry 1989; 46: 5117.

[304] Miaskiewicz SL, Stricker EM, Verbalis JG. Neurohypophyseal secretion in response to cholecystokinin but not meal-induced gastric distention in humans. J Clin Endocrinol Metab 1989; 68(4): $837-43$.

[305] Rex A, Barth T, Voigt J-P, Domeney AM, Fink H. Effects of cholecystokinin tetrapeptide and sulfated cholecystokinin octapeptide in rat models of anxiety. Neurosci Lett 1994; 172: 13942 .

[306] Kuwahara T, Kudoh T, Nakano A, et al. Species specificity of pharmacological characteristics of CCK-B receptors. Neurosci Lett $1993 ; 158(1): 1-4$

[307] Katsuura G, Itoh S, Hsiao S. Specificity of nucleus accumbens to activities related to cholecystokinins in rats. Peptides 1985; 6: 91-6.

[308] Vaccarino FJ, Arifuzzaman AI, Sabijan SM, et al. CCKB receptor activation and anxiogenic behavior: A neuroanatomical analysis. SfN Abstracts 1997; 23(2): 1621.

[309] Adler JL, Rowan CH, Geller EB. Intracerebroventricular vs subcutaneous drug administration: Apples and oranges? Neuropeptides 1984; 5: 73-6.

[310] Chopin P, Briley M. The benzodiazepine antagonist flumazenil blocks the effects of CCK receptor agonists and antagonists in the elevated plus maze. Psychopharmacology 1993; 110: 409-14.

[311] Fontaine R, Chouinard G, Annable L. Rebound anxiety in anxious patients after abrupt withdrawal of benzodiazepine treatment. Am J Psychiatry 1984; 141: 848-52.

[312] Otto MW, Pollack MH, Sachs GS, Reiter SR, Meltzer-Brody S, Rosenbaum JF. Discontinuation of benzodiazepine treatment: Efficacy of cognitive-behavioral therapy for patients with panic disorder. Am J Psychiatry 1993; 150(10): 1485-90.

[313] Singh L, Field MJ, Vass CA, Hughes J, Woodruff GN. The antagonism of benzodiazepine withdrawal effects by the selective cholecystokininB receptor antagonist CI-988. Br J Pharmacol 1992; 105: 8-10.

[314] Bouthillier A, de Montigny C. Long-term benzodiazepine treatment reduces neuronal responsiveness to cholecystokinin: An electrophysiological study in the rat. Eur J Pharmacol 1988; 151: $135-8$

[315] Harro J, Kiivet RA, Lang A, Vasar E. Rats with anxious or nonanxious type of exploratory behavior differ in their CCK-8 and benzodiazepine receptor characteristics. Behav Brain Res 1990; 39: 63-71.

[316] Harro J, Vasar E. Cholecystokinin-induced anxiety: How is it reflected in studies on exploratory behavior in the rat. Pharmacol Biochem Behav 1993; 15: 473-7.

[317] Palmour R, Bradwejn J, Ervin F. The anxiogenic effects of CCK-4 in monkeys are reduced by CCKB antagonists, benzodiazepines or adenosine A2 agonists. Eur J Neuropsychopharmacol 1992; 2: 1935.

[318] Rex A, Sondern U, Voigt JP, Franck S, Fink H. Strain differences in fear-motivated behavior of rats. Pharmacol Biochem Behav 1996; 54(1): 107-11

[319] Trullas R, Skolnick P. Differences in fear motivated behaviors among inbred mouse strains. Psychopharmacology 1993; 111: 3223-331.

[320] Shanks N, Griffiths J, Zalcman S, Zacharko RM, Anisman H. Mouse strain differences in plasma corticosterone following uncontrollable footshock. Pharmacol Biochem Behav 1990; 36: 515-9.

[321] van Megen HJGM, Westenberg HGM, Den Boer JA. Pentagastrin induced panic attacks: Enhanced sensitivity in panic disorder patients. Psychopharmacology 1994; 114: 449-55.

[322] van Megen HJGM, Westenberg HGM, Den Boer JA. Effect of the cholecystokinin-B receptor antagonist L-365, 260 on lactateinduced panic attacks in panic disorder patients. Biol Psychiatry 1996; 40: 804-6.
[323] Fortin G, Branchereau P, Araneda S, Champagnat J. Rhythmic activities in the rat solitary complex in vitro. Neurosci Lett 1992; 145: 23-7.

[324] Jhamandas JH, Harris KM. Influence of nucleus tractus solitarius stimulation and baroreceptor activation on rat parabrachial neurons. Brain Res Bull 1992; 28: 565-71.

[325] Derrien M, Durieux C, Dauge V, Roques BP. Involvement of D2 dopaminergic receptors in the emotional and motivational responses induced by injection of CCK-8 in the posterior part of the rat nucleus accumbens. Brain Res 1993; 617: 181-8.

[326] Zacharko RM, Koszycki D, Mendella PD, Bradwejn J. Behavioral, neurochemical, anatomical and electrophysiological correlates of panic disorder: Multiple transmitter interaction and neuropeptide colocalization. Prog Neurobiol 1995; 47: 371-423.

[327] Ravard S, Dourish CT. Cholecystokinin and anxiety. TiPS 1990; 11(7): 271-3.

[328] File SE, Zangrossi H. "One trial tolerance" to the anxiolytic actions of benzodiazepines in the elevated plus-maze, or the development of a phobic state? Psychopharmacology 1993; 110: 240-4

[329] File SE. The interplay of learning and anxiety in the elevated plus maze. Behavioral Brain Res 1993; 58: 199-202.

[330] Post RM, Weiss SR. Sensitization and kindling: Implications for the evolution of psychiatric symptomatology. In: Kalivas PW, Barnes CD, eds. Sensitization in the Nervous System. New Jersey: Telford Press 1988.

[331] Bradwejn J, Koszycki D. Imipramine antagonism of the panicogenic effects of cholecystokinin tetrapeptide in panic disorder patients. Am J Psychiatry 1994; 151(2): 261-3.

[332] Bradwejn J, Koszycki D, Paradis M, Reece P, Hinton J, Sedman A Effect of CI-988 on cholecystokinin tetrapeptide-induced panic symptoms in healthy volunteers. Biol Psychiatry 1995; 38: 742-6.

[333] van Megen HJGM, Westenberg HGM, den Boer JA, Slaap B, van Es-Radhakishum F, Pande AC. The cholecystokinin-B receptor antagonist CI-988 failed to affect CCK-4 induced symptoms in panic disorder patients. Psychopharmacology 1997; 129: 243-8.

[334] Benkelfat C, Bradwejn J, Meyer E, et al. Functional neuroanatomy of CCK-4-induced anxiety in normal healthy volunteers. Am J Psychiatry 1995; 152(8): 1180-4.

[335] Schunck T, Erb G, Mathis A, et al. Functional magnetic resonance imaging characterization of CCK-4-induced panic attack and subsequent anticipatory anxiety. NeuroImage 2006; 31: 1197-208.

[336] Bradwejn J, Koszycki D, Annable L, Couetoux du Tertre A, Reines S, Karkanias C. A dose-ranging study of the behavioral and cardiovascular effects of CCK-tetrapeptide in PD. Biol Psychiatry 1992; 32: 903-12.

[337] De Leeuw AS, Den Boer JA, Slaap BR, Westenberg HGM. Pentagastrin has panic inducing properties in obsessive-compulsive disorder. Psychopharmacology 1996; 126(4): 339-44.

[338] Bradwejn J, Koszycki D, Bourin M. Dose ranging study of the effect of CCK-4 in healthy volunteers. J Psychiatry Neurosci 1991; 16(260-264)

[339] Bradwejn J, Koszycki D, Shriqui C. Enhanced sensitivity to cholecystokinin tetrapeptide in panic disorder. Clinical and behavioral findings. Arch Gen Psychiatry 1991; 48: 603-10.

[340] Koszycki D, Torres S, Swain JE, Bradwejn J. Central cholecystokinin activity in irritable bowel syndrome, panic disorder, and health controls. Adv Psychos Med 2005; 67: 590-5.

[341] Battaglia M, Bertella S, Politi E, et al. Age at onset of panic disorder: Influence of familial liability to the disease and of childhood separation anxiety disorder. Am J Psychiatry 1995; 152(9): 1362-4.

[342] Miyasaka K, Kanai S, Masuda M, et al. Gene expressions of cholecystokinin (CCK) and CCK receptors, and its satiety effect in young and old male rats. Arch Gerontol Geriat 1995; 21: 147-55.

[343] Ohta M, Tanaka Y, Masuda M, Miyasaka K, Funakoshi A. Impaired release of cholecystokinin (CCK) from synaptosomes in old rats. Neurosci Lett 1995; 198: 161-4.

[344] Diagnostic and statistical manual of mental disorders (DSM-IV) Fourth edition. Washington, D. C.: American Psychiatric Association 1994.

[345] Scupi BS, Benson BE, Brown LB, Uhde TW. Rapid onset: a valid panic disorder disorder criterion? Depress Anxiety 1997; 5(3): 1216.

[346] Bradwejn J, Koszycki D. Comparison of the panicogenic effect of cholecystokinin 30-33 and carbon dioxide in panic disorder. 
Progress in Neuro-Psychopharmacol Biol Psychiatry 1991; 15: 237-9.

[347] Koszycki D, Bradwejn J, Bourin M. Comparison of the effects of cholecystokinin tetrapeptide and carbon dioxide in healthy volunteers. Eur Neuropsychopharmacol 1991; 1: 137-41.

[348] Kenardy J, Evans L, Oei TPS. The latent structure of anxiety symptoms in anxiety disorders. Am J Psychiatry 1992; 149(8): 1058-61.

[349] Goetz RR, Klein DF, Gully R, et al. Panic attacks during placebo procedures in the laboratory. Arch Gen Psychiatry 1993; 50: 280-5.

[350] Argyle N, Roth M. The definition of panic attacks, Part I. Psychiatry Dev 1989; 7(3): 175-86.

[351] Margraf J, Taylor B, Ehlers A, Roth WT, Agras WS. Panic attacks in the natural environment. J Nerv Ment Dis 1987; 175(9): 558-65.

[352] Albus M, Zahn TP, Breier A. Anxiogenic properties of yohimbine. II. Influence of experimental set and setting. Eur Arch Psychiatry Clin Neurosci 1992; 241: 345-51.

[353] Charney DS, Heninger GR, Breier A. Noradrenergic function in panic anxiety: Effects of yohimbine in healthy subjects and patients with agoraphobia and panic disorder. Arch Gen Psychiatry 1984; 41: 751-63.

[354] Albus M, Zahn TP, Breier A. Anxiogenic properties of yohimbine. I. Behavioral, physiological, and biochemical measures. Eur Arch Psychiatry Clin Neurosci 1992; 241: 337-44.

[355] Targum SD. Panic attack frequency and vulnerability to anxiogenic challenge studies. Psychiatric Res 1991; 36: 75-83.

[356] Rapee R, Mattick R, Murrell E. Cognitive mediation in the affective component of spontaneous panic attacks. J Behav Ther Exp Psychiatry 1986; 17(4): 245-53.

[357] Roth WT, Margraf J, Ehlers A, et al. Stress test reactivity in panic disorder. Arch Gen Psychiatry 1992; 49: 301-10.

[358] Sanderson W, Rapee R, Barlow DH. The influence of an illusion of control on panic attacks induced via inhalation of $5.5 \%$ carbon dioxide enriched air. Arch Gen Psychiatry 1989; 46: 157-62.

[359] Hoehn-Saric R, McLeod DR, Zimmerli WD. Psychophysiological response patterns in panic disorder. Acta Psychiatr Scand 1991; 83(1): 4-11

[360] Koszycki D, Cox BJ, Bradwejn J. Anxiety sensitivity and response to CCK-4 in healthy volunteers. Am J Psychiatry 1993; 150: 18813 .

[361] Harrington PJ, Schmidt NB, Telch MJ. Prospective evaluation of panic potentiation following $35 \% \mathrm{CO} 2$ challenge in nonclinical subjects. Am J Psychiatry 1996; 153(6): 823-5.

[362] Nutt DJ, Glue P. Clinical pharmacology of anxiolytics and antidepressants: A psychopharmacological perspective. In: File SE, ed. Psychopharmacology of Anxiolytics and Antidepressants. New York: Pergamon Press 1991.

[363] Bakish D, Saxena BM, Bowen R, D'Souza J. Reversible monoxidase-A inhibitors in panic disorder. Clin Neuropharmacol 1993; 16(Suppl 2): S77-S82.

[364] Bandelow B, Sievert K, Rothemeyer M, Hajak G, Ruther E. What treatments do patients with panic disorder and agoraphobia get? Eur Arch Psychiatry Clin Neurosci 1995; 245(3): 165-71.

[365] Buller R. Reversible inhibitors of monoamine oxidase A in anxiety disorders. Clin Neuropharmacol 1995; 18(Suppl 2): S38-S44.

[366] Curtis GC, Massana J, Udina C, Ayuso JL, Cassano GB, Perugi G. Maintenance drug therapy of panic disorder. J Psychiatr Res 1993; 27(Suppl 1): 127-42.

[367] De La Fuente JR. Long-term management of panic disorder. Curr Ther Res 1993; 54(6): 838-51.

[368] Evans L, Kenardy J, Schneider P, Hoey H. Effect of a selective serotonin uptake inhibitor in agoraphobia with panic attacks. A double blind comparison of zimeldine, imipramine and placebo. Acta Psychiatr Scand 1986; 73: 49-53.

[369] Keck PE, McElroy SL, Tugrul KC, Bennett JA, Smith JMR. Anitepileptic drugs for the treatment of panic disorder. Neuropsychobiology 1993; 27: 150-3.

[370] Rosenberg R, Bech P, Mellegard M, Ottosson JO. Alprazolam, imipramine, and placebo treatment of panic disorder: Predicting therapeutic response. Acta Psychiatr Scand 1991; 365(Suppl): 4652.

[371] Rosenberg R, Bech P, Mellegard M, Ottosson JO. Secondary depression in panic disorder: An indicator of severity with a weak effect on outcome in alprazolam and imipramine treatment. Acta Psychiatr Scand 1991; 365(Suppl): 39-45.
[372] Yonkers KA, Ellison JM, Shera DM, et al. Description of antipanic therapy in a prospective longitudinal study. J Clin Psychopharmacol 1996; 16(3): 223-32.

[373] Charney DS, Heninger GR. Noradrenergic function and the machanism of action of antianxiety treatment. The effect of longterm alprazolam treatment. Arch Gen Psychiatry 1985; 42(5): 45867.

[374] Ko GN, Elsworth JD, Roth RH, Rifkin BG, Leigh H, Redmond E. Panic induced elevation of plasma MHPG levels in phobic-anxious patients. Effects of clonidine and imipramine. Arch Gen Psychiatry 1983; 40: 425-30.

[375] Sugrue MF. Current concepts on the mechanisms of action of antidepressant drugs. Pharmacol Ther 1981; 13: 219-47.

[376] Fuxe K, Ogren SO, Agnati LF, Andersson K, Eneroth P. Effects of subchronic antidepressant drug treatment on central serotonergic mechanisms in the male rat. Adv Biochem Psychopharmacol 1982; 31: 91-107.

[377] Johanning H, Plenge P, Mellenrup E. Serotonin receptors in the brain of rats treated chronically with imipramine or RU 24969 : Support for the 5-HTIB receptor being a 5-HT autoreceptor. Pharmacol Toxicol 1992; 70(2): 131-4.

[378] Svensson TH. Effect of chronic treatment with tricyclic antidepressant drugs on identified brain noradrenergic and serotonergic neurons. Acta Psychiatr Scand 1980; 61(Suppl 280): 121-31.

[379] Zitrin CM. Differential treatment of phobias: Use of imipramine for panic attacks. J Behav Ther Exp Psychiatry 1983; 14(1): 11-8.

[380] Sethy VH, Hodges DH. Alprazolam in a biochemical model of depression. Biochem Pharmacol 1982; 31(19): 3155-7.

[381] Miller LG, Greenblatt DJ, Barnhill JG, Deutsch SI, Shader RI, Paul SM. Benzodiazepine receptor binding of triazolbenzodiazepines in vivo: increased receptor number with low-dose alprazolam. J Neurochem 1987; 49(5): 1595-601.

[382] Kaschka W, Feistel H, Ebert D. Reduced benzodiazepine receptor binding in panic disorders measured by iomazenil spect. J Psychiatr Res 1995; 29(5): 427-34.

[383] Sevy S, Brown S-L, Wetzler S, et al. Effects of alprazolam on increases in hormonal and anxiety levels induced by metachlorophenylpiperazine. Psychiatry Res 1994; 53: 219-29.

[384] Jonas JM, Cohon MS. A comparison of the safety and efficacy of alprazolam versus other agents in the treatment of anxiety, panic, and depression: A review of the literature. J Clin Psychiatry 1993; 54(10): 25-45.

[385] Mellergard M, Lorentzen K, Bech P, Ottosson J-O, Rosenberg R. A trend analysis of changes during treatment of panic disorder with alprazolam and imipramine. Acta Psychiatr Scand 1991; 365(Suppl): 28-32.

[386] King D, Nicolini H, De La Fuente JR. Abuse and withdrawal of panic treatment drugs. Psychiatric Ann 1990; 20(9): 525-8.

[387] Mavissakalian M, Perel JM. Protective effects of imipramine maintenance treatment in panic disorder with agoraphobia. Am J Psychiatry 1992; 149(8): 1053-7.

[388] Pecknold J. Discontinuation reactions to alprazolam in panic disorder. J Psychiatr Res 1993; 27(Suppl 1): 155-170.

[389] Amrein R, Allen SR, Vrasanic D, Stahl M. Antidepressant drug therapy: Associated risk. J Neural Transm 1988; 26(Suppl): 73-86.

[390] Andersch S, Rosenberg NK, Kullingsjo H, et al. Efficacy and safety of alprazolam and placebo in treating panic disorder. A Scandinavian multicenter study. Acta Psychiatr Scand 1991; 365(Suppl): 18-27.

[391] Fux M, Taub M, Zohar J. Emergence of depressive symptoms during treatment for panic disorder with specific 5-hydroxytryptophan reuptake inhibitors. Acta Psychiatr Scand 1993; 88: 235-7.

[392] Hetem LAB. Addition of d-fenfluramine to benzodiazepines produces a marked improvement in refractory panic disorder - A case report. J Clin Psychopharmacol 1996; 16(1): 77-8.

[393] Hoehn-Saric R, McLeod DR, Hipsley PA. Effect of fluvoxamine on panic disorder. J Clin Psychopharmacol 1993; 13(5): 321-6.

[394] Klein DF. Treatment of panic disorder, agoraphobia, and social phobia. Clin Neuropharmacol 1995; 18(Suppl 2): S45-S51.

[395] Taylor CB, Hayward C, King R, et al. Cardiovascular and symptomatic reduction effects of alprazolam and imipramine in patients with panic disorder: Results of a double-blind, placebocontrolled trial. J Clin Psychopharmacol 1990; 10(2): 112-8. 
[396] Rizley R, Kahn RJ, McNair DM, Frankenthaler LM. A comparison of alprazolam and imipramine in the treatment of agoraphobia and panic disorder. Psychopharmacol Bull 1986; 22: 167-72.

[397] Schweizer E, Rickels K, Weiss S, Zavodnick S. Maintenance drug treatment of panic disorder. I. Results of a prospective, placebocontrolled comparison of alprazolam and imipramine. Arch Gen Psychiatry 1993; 50: 51-60.

[398] Cassella J, Davis M. Fear-enhanced startle is not attenuated by acute or chronic imipramine treatment in rats. Psychopharmacology 1985; 87: 278-82

[399] Hijzen TH, Houtzager SWJ, Joordens RJE, Olivier B, Slangen JL. Predictive validity of the potentiated startle response as a behavioral model for anxiolytic drugs. Psychopharmacol 1995; 118: $150-4$.

[400] Duncan GE, Breese GR, Criswell H, Stumpf WE, Mueller RA, Covey JB. Effects of antidepressant drugs injected into the amygdala on behavioral responses of rats in the forced swim test. J Pharmacol Exp Ther 1986; 238(2): 758-62.

[401] Harris JA, Westbrook RF. Effects of benzodiazepine microinjection into the amygdala or periaqueductal gray on the expression of conditioned fear and hypoalgesia in rats. Behav Neurosci 1995; 109(2): 295-304.

[402] Pesold C, Treit D. The central and basolateral amygdala differentially mediate the anxiolytic effects of benzodiazepines. Brain Res 1995; 671(2): 213-21

[403] Shimazoe T, Shibata S, Yatsugi S, Ueki S. Involvement of the medial amygdaloid nucleus in the action of imipramine in rats subjected to the forced swimming test. J Pharmacobio-Dynamics 1988; 11: 137-9.

[404] Shirayama Y, Mitsushio H, Takashima M, Ichikawa H, Takahashi K. Reduction of substance $\mathrm{P}$ after chronic antidepressants treatment in the striatum, substantia nigra and amygdala of the rat. Brain Res 1996; 739(1-2): 70-8.

[405] Davis M, Rainne D, Cassell M. Neurotransmission in the rat amygdala related to fear and anxiety. TiNs 1994; 17(5): 208-14.

[406] Kunas G, Varga K. The tachycardia associated with the defense reaction involves activation of both GABAA and GABA B receptors in the nucleus tractus solitarii. Clin Exp Hypertens 1995; 17(1): 91-100.

[407] Walker DL, Davis M. Double dissociation between the involvement of the bed nucleus of the stria terminalis and the central nucleus of the amygdala in startle increases produced by conditioned versus unconditioned fear. J Neurosci 1997; 17(23): 9375-83.

[408] Rosenberg NK, Mellegard M, Rosenberg R, Bech P, Ottosson JO. Characteristics of panic patients responding to placebo. Acta Psychiatr Scand 1991; 365(Suppl): 33-8.

[409] Woodman CL, Noyes R, Ballenger JC, Lydiard RB, Sievers G, Mihalko D. Predictors of response to alprazolam and placebo in patients with panic disorder. J Affect Disord 1994; 30: 5-13.

[410] Barlow DH, Dinardo PA, Vermilyea BB, Vermilyea J, Blanchard EB. Co-morbidity and depression among the anxiety disorders: Issues in diagnosis and classification. J Nerv Ment Dis 1986; 174: 63-72.

[411] Wittchen HU. Natural course and spontaneous remissions of untreated anxiety disorders: Results of the Munich follow-up study. In: Hand I, Wittchen HU, eds. Panic and Phobia 2: Treatment and Variables Affecting Course and Outcome. Berlin: Springer-Verlag 1988: 3-17.

[412] Marks IM, O'Sullivan G. Anti-anxiety drug and psychological treatment effects in agoraphobia/panic and obsessive-compulsive disorders. In: Tyrer P, ed. Psychopharmacology of Anxiety. New York: Oxford University Press 1987.

[413] van Valkenburg C, Winokur G, Behar D, Lowry M. Depressed women with panic attacks. J Clin Psychiatry 1984; 45(9): 367-9.

[414] Cassano GB, Toni C, Musetti L, Mengali F, Perugi G. Prophylactic utility and consequences of long-term medication in panic disorder. Current Therapeutic Approaches to Panic and Other Anxiety Disorders. Int Acad Biomed Drug Res 1994; 8: 36-42.

[415] Keller MB, Lavori PW, Goldenberg IM, et al. Influence of depression on the treatment of panic disorder with imipramine, alprazolam and placebo. J Affect Disord 1993; 28: 27-38.

[416] Klein DF. The cause and treatment of agoraphobia. Arch Gen Psychiatry 1988; 45: 388-92.
[417] Pyke RE, Kraus M. Alprazolam in the treatment of panic attack patients with and without major depression. J Clin Psychiatry 1988; 49(2): 66-8.

[418] Kayser A, Robinson DS, Yingling K, Howard DB, Corcella J, Laux D. The influence of panic attacks on resonse to phenelzine and amitriptyline in depressed outpatients. J Clin Psychopharmacol 1988; 8(4): 246-53.

[419] Roy-Byrne PP, Vitaliano PP, Cowlry DS, Luciano G, Zheng Y, Dunner DL. Coping in panic and major depressive disorder. Relative effects of symptom severity and diagnostic comorbidity. J Nerv Ment Dis 1992; 180(3): 179-83.

[420] Cox BJ, Dirinfeld DM, Swinson RP, Norton GR. Suicidal ideation and suicide attempts in panic disorder and social phobia. Am J Psychiatry $1994 ; 151(6)$ : 882-7.

[421] Buffone GW. Treatment of panic disorder: An overview. Med Psychother 1991; 4: 131-44.

[422] Grunhaus L, Pande A, Brown MB, Greden JF. Clinical characteristics of patients with concurrent major depressive disorder and panic disorder. Am J Psychiatry 1994; 151(4): 541-6.

[423] Davidson J, Raft D, Pelton S. An outpatient evaluation of phenelzine and imipramine. J Clin Psychiatry 1987; 48: 143-6.

[424] Quitkin FM, Stewart JW, McGrath PJ, et al. Phenelzine versus imipramine in the treatment of probable atypical depression: defining syndrome boundaries of selective MAOI responders. Am J Psychiatry 1988; 145(3): 306-11.

[425] Scheibe G, Albus M. Predictors of outcome in panic disorder: A 5year prospective follow-up study. J Affect Disord 1996; 41: 111-6.

[426] Klein DF, Ross DC, Cohen P. Panic and avoidance in agoraphobia. Arch Gen Psychiatry 1987; 44: 377-89.

[427] Abelson JL, Curtis GC, Cameron OG. Hypothalamic-pituitaryadrenal axis activity in panic disorder: Effects of alprazolam on $24 \mathrm{~h}$ secretion of adrenocorticotropin and cortisol. J Psychiatr Res 1996; 30(2): 79-93.

[428] Abelson JL, Curtis GC, Nesse RM, R F, Pyke RE, BammertAdams J. The effects of central cholecystokinin receptor blockade on hypothalamic-pituitary-adrenal and symptomatic responses to overnight withdrawal from alprazolam. Biol Psychiatry 1995; 37: 56-9.

[429] Mavissakalian MR. Phenomenology of panic attacks: responsiveness of individual symptoms to imipramine. J Clin Psychopharmacol 1996; 16(3): 233-7.

[430] Pilowsky I. Dimensions of hypochondriasis. Br J Psychiatry 1967; 113: 89-93.

[431] Noyes R, Reich J, Clancy J, O'Gorman TW. Reduction in hypochondriasis with treatment of panic disorder. Br J Psychiatry 1986; 149: 631-5.

[432] Albus M, Lecrubier Y, Maier W, Buller R, Rosenberg R, Hippius H. Drug treatment of panic disorder: Early response to treatment as a predictor of final outcome. Acta Psychiatr Scand 1990; 82: 359 65.

[433] Slaap BR, van Vliet IM, Westenberg HGM, den Boer JA. Phobic symptoms as predictors of nonresponse to drug therapy in panic disorder patients (a preliminary report). J Affect Disord 1995; 33: 31-8.

[434] Bakish D. The use of the reversible monoamine oxidase-A inhibitor brofaromine in social phobia complicated by panic disorder with or without agoraphobia. J Clin Psychopharmacol 1994; 14(1): 74-5.

[435] Barlow DH, Craske MG, Cerny JA, Klosko JS. Behavioral treatment of panic disorder. Behav Ther 1989; 20: 261-82.

[436] Clark DM. Cognitive therapy in the treatment of anxiety disorders. Clin Neuropharmacol 1995; 18(Suppl 2): S27-S37.

[437] Robins CJ, Hayes AD. An appraisal of cognitive therapy. J Consult Clin Psychol 1993; 61(2): 205-14.

[438] Klosko JS, Barlow DH, Tassinari R, Cerny JA. A comparison of alprazolam and behavior therapy in treatment of panic disorder. J Consult Clin Psychol 1990; 58(1): 77-84.

[439] Nagy LM, Krystal JH, Charney DS, Merikangas KR, Woods SW. Long-term outcome of panic disorder after short-term imipramine and behavioral group treatment: 2.9-year naturalistic follow-up study. J Clin Psychopharmacol 1993; 13(1): 16-24.

[440] Spiegel DA, Bruce TJ, Gregg SF, Nuzzarello A. Does cognitive behavior therapy assist slow-taper alprazolam discontinuation in panic disorder. Am J Psychiatry 1994; 151(6): 876-81.

[441] Williams SL, Kinney PJ, Falbo J. Generalization of therapeutic changes in agoraphobia: The role of perceived self-efficacy. J Consult Clin Psychol 1989; 57(3): 436-42. 
[442] Noyes R, Garvey MJ, Cook BL. Follow-up study of patients with panic disorder and agoraphobia with panic attacks treated with tricyclic antidepressants. J Affect Disord 1989; 16: 249-57.

[443] Free NK, Winget CN, Whitman RM. Separation anxiety in panic disorder. Am J Psychiatry 1993; 150(4): 595-9.

[444] Klein DF. Is panic disorder assocaited with childhood separation anxiety disorder? Clin Neuropharmacol 1995; 18(Suppl 2): S7-S14.

[445] Pollack MH, Otto MW, Sabatino S, et al. Relationship of childhood anxiety to adult panic disorder: Correlates and influence on course. Am J Psychiatry 1996; 153(3): 376-81.

[446] Kraemer GW. A psychobiologic theory of attachment. Brain Behav Sci 1992; 15: 493-541.

[447] Roth M. The panic-agoraphobic syndrome: A paradigm of the anxiety group of disorders and its implications for psychiatric practice and theory. Am J Psychiatry 1996; 153(7): 111-24.

[448] Rosenbaum JF, Biederman J, Gersten M, et al. Behavioral inhibition in children of parents with panic disorder and agoraphobia: A controlled study. Arch Gen Psychiatry 1988; 45: 463-70.

[449] Lepola U, Leinonen E, Koponen H. Citalopram in the treatment of early-onset panic disorder and school phobia. Pharmacopsychiatry 1996; 29: 30-2.

[450] David D, Giron A, Mellman TA. Panic-phobic patients and developmental trauma. J Clin Psychiatry 1995; 56(3): 113-7.

[451] Otto MW, Pollack MH, Rosenbaum JF, Sachs GS, Asher RH. Childhood history of anxiety in adults with panic disorder:
Association with anxiety sensitivity and avoidance. Harv Rev Psychiatry 1994; 1: 288-93.

[452] Zacharko RM, Anisman H. Motor, motivational and antinocioceptive consequences of stress: contribution of neurochemical change. In: Tricklebank MD, Curzon G, eds. Stress-Induced Analgesia. Chichester: Wiley 1984: 33-65.

[453] Zacharko RM, Anisman H. Stressor induced anhedonia in the mesocorticolimbic system. Neurosci Biobehav Rev 1991; 15: 391 405.

[454] Cox BJ, Endler NS, Swinson RP. An examination of levels of agoraphobia severity in panic disorder. Behav Res Ther 1995; 33(1): 57-62.

[455] Akiyoshi J, Moriyama T, Isogawa K, et al. CCK-4 induced calcium mobilization in T cells is enhanced in panic disorder. J Neurochem 1996; 66(4): 1610-6.

[456] Owens MJ, Bissette G, Nemeroff CB. Acute effects of alprazolam and adinazolam on the concentrations of corticotropin-releasing factor in the rat brain. Synapse 1989; 4(3): 196-202.

[457] Owens MJ, Varfas MA, Nemeroff CB. The effects of alprazolam on corticotropin-releasing factor neurons in the rat brain: Implications for a role for $\mathrm{CRF}$ in the pathogenesis of anxiety disorders. J Psychiatr Res 1993; 27(Suppl 1): 209-20.

[458] Milrod B, Busch F. Long-term outcome of panic disorder treatment: a review of the literature. J Nerv Ment Dis 1996; 184(12): 723-30. 